\title{
CHANGING VULNERABILITY IN ASIA: CONTAGION AND SYSTEMIC RISK
}

Mardi Dungey, Moses Kangogo, and Vladimir Volkov

NO. 583

May 2019
ADB ECONOMICS WORKING PAPER SERIES 
ADB Economics Working Paper Series

\section{Changing Vulnerability in Asia: Contagion and Systemic Risk}

Mardi Dungey, Moses Kangogo, and Vladimir Volkov

No. 583 | May 2019
Mardi Dungey is a former professor, Moses Kangogo (moses.kangogo@utas.edu.au) is a doctoral researcher, and Vladimir Volkov (vladimir.volkov@utas.edu.au) is a lecturer in the Tasmanian School of Business and Economics, University of Tasmania. 
(C) 2019 Asian Development Bank 6 ADB Avenue, Mandaluyong City, 1550 Metro Manila, Philippines

Tel +632632 4444; Fax +6326362444

www.adb.org

Some rights reserved. Published in 2019.

ISSN 2313-6537 (print), 2313-6545 (electronic)

Publication Stock No. WPS190180-2

DOI: http://dx.doi.org/10.22617/WPS190180-2

The views expressed in this publication are those of the authors and do not necessarily reflect the views and policies of the Asian Development Bank (ADB) or its Board of Governors or the governments they represent.

ADB does not guarantee the accuracy of the data included in this publication and accepts no responsibility for any consequence of their use. The mention of specific companies or products of manufacturers does not imply that they are endorsed or recommended by ADB in preference to others of a similar nature that are not mentioned.

By making any designation of or reference to a particular territory or geographic area, or by using the term "country" in this document, $A D B$ does not intend to make any judgments as to the legal or other status of any territory or area.

This work is available under the Creative Commons Attribution 3.0 IGO license (CC BY 3.0 IGO)

https://creativecommons.org/licenses/by/3.o/igo/. By using the content of this publication, you agree to be bound by the terms of this license. For attribution, translations, adaptations, and permissions, please read the provisions and terms of use at https://www.adb.org/terms-use\#openaccess.

This CC license does not apply to non-ADB copyright materials in this publication. If the material is attributed to another source, please contact the copyright owner or publisher of that source for permission to reproduce it. $\mathrm{ADB}$ cannot be held liable for any claims that arise as a result of your use of the material.

Please contact pubsmarketing@adb.org if you have questions or comments with respect to content, or if you wish to obtain copyright permission for your intended use that does not fall within these terms, or for permission to use the ADB logo.

Corrigenda to ADB publications may be found at http://www.adb.org/publications/corrigenda.

Notes:

In this publication, "\$” refers to United States dollars.

ADB recognizes "China" as the People's Republic of China.

The ADB Economics Working Paper Series presents data, information, and/or findings from ongoing research and studies to encourage exchange of ideas and to elicit comment and feedback about development issues in Asia and the Pacific. Since papers in this series are intended for quick and easy dissemination, the content may or may not be fully edited and may later be modified for final publication. 


\section{CONTENTS}

TABLES AND FIGURES

iv

ABSTRACT V v v v v

$\begin{array}{ll}\text { I. INTRODUCTION } & 1\end{array}$

II. LITERATURE REVIEW 2

III. DETECTING CONTAGION AND VULNERABILITY 5

A. $\quad$ Spillovers Using the Generalized Historical Decomposition Methodology 6

B. Contagion Methodology 8

C. Estimation Strategy 11

IV. $\quad$ DATA AND STYLIZED FACTS 11

V. $\quad$ RESULTS AND ANALYSIS 13

A. $\quad$ Evidence for Spillovers $\quad 15$

B. Evidence for Contagion $\quad 27$

VI. IMPLICATIONS

$\begin{array}{lll}\text { VII. CONCLUSION } & 34\end{array}$

$\begin{array}{ll}\text { REFERENCES } & 37\end{array}$ 


\section{TABLES AND FIGURES}

\section{TABLES}

1 Markets in the Sample 12

2 Phases of the Sample 13

3 Descriptive Statistics of Each Equity Market Return 14

4 Historical Decomposition for the 2003-2017 Sample Period 16

5 Historical Decomposition for the 2003-2008 Pre-Global Financial Crisis Sample Period 17

6 Historical Decomposition for the 2008-2010 Global Financial Crisis Sample Period 20

$7 \quad$ Historical Decomposition for the 2010-2013 European Debt Crisis Sample Period 21

8 Historical Decomposition for the 2013-2017 Most Recent Sample Period 22

9 Summary of Spillovers from and to the People's Republic of China and the United States 23 by Other Markets

10 United States and the People's Republic of China Results Using Forbes-Rigobon 28 Uncorrected and Corrected Tests, and Dungey-Renault Test

11 Estimates of $b$ for Each Subperiod with Mimicking Factor Given by the United States Market 29

12 Estimates of $b$ for Each Subperiod with Mimicking Factor Given by the People's Republic 32 of China Market

\section{FIGURES}

$1 \quad$ Equity Market Indexes, 2003-2017 12

2 Average Shocks Reception and Transmission by Period and Market 18

3 Receiving and Transmitting Spillovers to and from the United States and the People's 25

Republic of China

$4 \quad$ Spillover Index Based on Diebold-Yilmaz and Generalized Historical Decomposition 26

5 Structural Transmission Parameter to and from the People's Republic of China and 30 the United States 


\begin{abstract}
This paper investigates the changing network of financial markets between Asian markets and those of the rest of the world during January 2003-December 2017 to capture both the direction and strength of the links between them. Because each market chooses whether to connect with emerging markets as a bridge to the wider network, there are advantages to having access to this bridge for protection during periods of financial stress. Both parties gain by overcoming the information asymmetry between emerging and global markets. We analyze networks for four key periods, capturing networks in financial markets before and after the Asian financial crisis and the global financial crisis. Increased connections during crisis periods are evident, as well as a general deepening of the global network. The evidence on Asian market developments suggests caution is needed on regulations proposing methods to create stable networks, because these may result in reduced opportunities for emerging markets.
\end{abstract}

Keywords: Asian markets, financial crises, networks

JEL codes: C21, N25, G01, G15 


\section{INTRODUCTION}

Financial stability is one of the most important means of reducing economic uncertainty, enabling flows of investment funds and long-term decision making by policy makers and investors. Financial resilience, however, is also valued for its ability to absorb shocks, protecting countries from making costly short-term adjustments in the real economy via employment or inflation. Finding a balance between these competing aims is the critical path for policy makers. Agendas for reforming finance sectors after a crisis are documented at least as far back as the first half of 17th century Britain. 'The solutions proposed, unsurprisingly, seemed to depend on which part of the financial system had most recently failed. After the 1997-1998 Asian financial crisis, the issue was the international financial architecture. After the 2008 global financial crisis, it was credit risk transfer and macrofinancial integration-and the European debt crisis of 2011-2012 has refocused efforts on the nexus between sovereign debt and banks.

A common thread throughout these events is the transmission of shocks in one market to another. When a market is dependent on another market for the flow of capital and goods then their economies are intrinsically linked. This is the same at the local or subregional level. The distinguishing feature for countries, however, is that there are no cross-market agencies that can smooth the effects of the transmission easily via redistributive policies. The residents of one country cannot simply be compensated for changes in the preferences of the residents of the other country in the same way that intranational compensations occur. Some degree of adjustment costs will accrue to the recipient country (for example, the trade partners), and its policy makers can either do little to ameliorate them or they will need to somehow fund the offsets. These policy makers will seek to avoid, or at least minimize, these costs. Asymmetries exist of course in this relationship. Sometimes changes occurring in one country provide positive effects to others; for example, the discovery of a scarce resource. But mostly the effects of these positive chances are eagerly accrued.

The problem for policy makers is to understand how much stability is desirable and how to detect, monitor, and respond to changes in the transmission of the effects from one self-governing area to another. One step in this process is to distinguish the types of transmission that can occur and determine how to measure them. We can then work out which of the effects are (arguably) more important, using some form of welfare objective function, and then consider options for responding to the different types of transmissions.

This paper investigates empirically the distinct roles of spillovers and contagion in financial stability, carefully distinguishing between the two. Spillovers reflect the "expected" relationships between financial markets on the basis of underlying trade or banking relationships even though a fundamental set of determinants has yet to be established. The critical aspect of spillovers is that it can be anticipated how a shock in one market can transmit to another via, for example, balance sheets or trade and portfolio movements. In general, spillovers are stable, and changes are likely to be relatively slow moving (or the changes can be constructed across a continuous space).

Unlike spillovers, contagion is abrupt and unexpected. Its transmission goes beyond that which would normally be anticipated. The term is generally used in a negative sense, so that true contagion refers to a case where a shock in one market results in an unexpected decline in the performance of another. But there may also be cases where a shock in one market causes an unexpectedly smaller

\footnotetext{
Supple (1959) meticulously documents the policy discussions on the effects of international shocks on the British
} economy that was transmitted via the cloth trade and its consequent effect on the structure and stability of the economy. 
change in the performance of another. This is known as decoupling. Interdependence is maintained when markets respond to a shock by neither decoupling or through contagion effects; that is, the spillover effects from previously held relationships are maintained, albeit with higher or lower volatility in the market.

The distinctions between spillovers, contagion, and decoupling (and interdependence) are important for designing policies for financial stability. It is also important to recognize that no objective criteria are available to distinguish a change that is abrupt or gradual, so that distinguishing spillovers from contagion can be disputed. Allen and Wood (2006) discuss how to determine the appropriate speed of adjustment in markets. An asymmetric policy response may be needed to capture only the shocks that are going to have negative effects on the recipient economy. In different circumstances, spillover, contagion, or decoupling could either be undesirable or have useful outcomes. The problem is similar to that of research and development spillovers where there are offsetting effects from having rivals in product markets and technology spillovers (Lucking, Bloom, and Van Reenen 2018). ${ }^{2} \mathrm{~A}$ related problem is the complexity of trading off the continuous benefits of a more competitive banking sector against the costs of infrequent crises analyzed in Allen and Gale (2004). ${ }^{3}$

The literature on financial stability is vast. It attempts questions as diverse as the definition of financial stability (Allen and Wood 2006); the tensions between competition and regulation, and the sources of shocks via network theory (Acemoglu, Ozdaglar, and Tahbaz-Salehi 2015); credit risk transfer; shadow banking; and the international transfer of shocks, to name just a few of the most prominent areas of research on financial stability. This paper concentrates on the evidence for monitoring and assessing the transmission of spillovers and contagion across international boundaries. Given this focus, we are not concerned with the ultimate source of the problems, which may well lie with a real economy shock in some jurisdictions, but rather with the impact and implications of the transmissions of spillovers across the global financial markets.

\section{LITERATURE REVIEW}

Detecting evidence of the changing nature of the transmission of shocks has generated a considerable body of literature in the last 2 decades. Many papers have used correlation-based tests (detecting the presence of contagion) to detect the unexpected changes in transmission from Asian markets to international markets where the Asian markets are used as the source of potentially contagious shocks. This was particularly true during the Asian financial crisis and the literature on this includes Forbes and Rigobon (2002), who use Hong Kong, China as the source of shocks to other markets in a bivariate correlation framework; Sander and Kleimeier (2003), who look for contagion within Asia and from Asia to other emerging markets using Granger causality tests; Baur and Schulze (2005), who consider quantile regressions in a coexceedance framework for shocks from Thailand and Hong Kong, China to other Asian and international markets; and Baur and Fry (2009), who use both cross-section and time series identification to estimate the spread of contagion within Asian markets. Much of the literature on measuring the contagion from the Asian financial crisis is reviewed in Dungey, Fry, and Martin (2004). Since then, new methods have emerged that have also been tested on the dataset for the Asian financial crisis, including the generalized autoregressive conditional heteroskedasticity

2 They conclude that the positive aspects of research and development spillovers overwhelm the negative in welfare analysis.

3 See Fu, Lin, and Molyneux (2014) for an Asia and Pacific application. Zigraiova and Havranek (2016) review the empirical literature and find little meta evidence supporting the trade-off between banking sector competition and financial fragility. 
(GARCH) process (Dungey et al. 2015), dynamic conditional correlations (Chiang, Jeon, and Li 2007), smooth transition and indexes and other time-varying models (Kim, Kim, and Lee 2015), and copulas (Busetti and Harvey 2011).

A smaller body of literature considers Asian markets in terms of how they were affected by shocks originating elsewhere. Hwang et al. (2013) and Kim, Kim, and Lee (2015) consider the impact of the United States (US) financial crisis on emerging markets, for example. Kim, Kim, and Lee (2015) also draw attention to the importance of examining this issue for interventions to protect Asian economies from crises emanating elsewhere. ADB (2017) also investigates whether crises from other economies have an effect on Asian economies. Beirne et al. (2010) consider local, regional, and global effects for 41 emerging markets, and conclude that significant spillovers from global effects cannot be rejected in Asian markets. Morabek et al. (2016) use all possible pairings between 20 emerging and developed markets, including six in Asia, in a dynamic conditional correlation mixed-data sampling framework to conclude that there are many different and time-varying relationships between them that will affect the efficacy of policy making. These multivariate approaches are typically based on equity market data and either consider particular subgroups of countries or bundle Asian markets together.

The increasing importance of Asian financial markets in the global economy, especially the People's Republic of China (PRC), has led to the growth of literature focusing on the spillovers between financial markets in Asia and other markets, both regional and international. Spillovers are the normal flow of information and adjustment of portfolios between markets, although this does not imply that spillovers are static. Yilmaz (2010) produces a time-varying spillover index for East Asian markets. Spillovers do not capture the abrupt changes associated with stress caused by contagion. They instead evolve relatively slowly with increasing financial integration, trade relationships, and the normal course of business and expansion. The literature comparing these types of channels includes Van Rijckeghem and Weder (2001) and Dungey, Khan, and Raghavan (2018).

Given the growth in the size and relative importance of Asian markets, we have good reason to believe that the relationships between Asian and global financial markets have changed since the start of the 21st century in response to both changing cross-region relationships and periods of financial stress experienced as crises since 2000. This paper examines the January 2003-December 2017 period from the perspective of an Asia-focused global market. We aim to investigate the evidence for contagion and the time evolution of spillovers from the global market affecting Asia and compare this evidence with regionally sourced influences. In common with the literature, we focus on contagion and spillover by considering the influence of the PRC and US markets. US markets are used as a proxy for global conditions in, among others, Chiang, Jeon, and Li (2007) and Kim, Kim, and Lee (2015). Dungey and Vehbi (2015) compare the influences of the PRC and the US. It is worth noting that Kim, Kim, and Lee $(2015,193)$ argue vigorously against including the PRC as a source of spillovers and contagion in financial market integration studies because of a perceived lack of market freedom in determining observed outcomes. Arslanalp et al. (2016) examine the growing role of spillovers from the PRC to other Asian financial markets. Yilmaz (2010) tests whether the inclusion of India and the PRC are important for calculating a spillover index for the region; they find that the impact is evident only after 2002.

We implement the recently developed spillover and connectedness methods for detecting and measuring spillovers and contagion. The spillover method builds on the index developed by Diebold and Yilmaz $(2009,2014)$, which provides a summary measure of financial spillovers in a network of markets based on a forecast error variance decomposition of a vector autoregression (VAR) of the 
returns data. The Diebold-Yilmaz connectedness index has attracted a great deal of attention in the literature as a means of determining building pressure in spillovers between markets. The index is applied in Diebold and Yilmaz (2009, 2012, 2014, 2015); Demirer et al. (2018); and Yilmaz (2010), among others. Dungey et al. (2018) show that by rearranging information in the same VAR structure, it is possible to obtain information on not only the source of the spillovers affecting each market and the extent to which spillovers from one market affect others, but also to sign these effects.

The signing of spillover effects is important because it allows us to assess whether transmission via spillovers is acting to amplify or dampen the shocks originating from one market and affecting others. In general, links that amplify the transmission of bad shocks to other markets are undesirable during crisis periods, and we argue that these are the ones policy makers should be most concerned to attenuate. To do this, it is important to be able to distinguish amplifying shocks from dampening shocks - that is, when an outcome from one market is dampened in its transmission, it contributes to the usually desirable outcome of reducing the volatility in the recipient market because of the spillovers. Dampening shocks lead to undesirable outcomes if paths that provide counterbalancing measures are inadvertently shut down in the haste to block potentially harmful transmission paths. For this reason, we introduce a time-varying measure of both the size and direction of the contributions of spillovers to the transmission of shocks between markets.

Contagion effects introduced among the first mention of original literature that include Forbes and Rigobon (2002), were mainly considered to have a negative impact. The contagion effect was introduced as a one-sided test where the correlation between asset markets was increased beyond what would have been expected during normal conditions - and even after controlling for increased volatility in market conditions. This increased volatility is regarded as undesirable because it can lead to a flight to quality, leverage effects, and a flight to home or a flight to familiarity. A flight to home and a flight to familiarity can be attributed to increased risk and uncertainty in both markets experiencing crisis and those associated with them (Giannetti and Laeven 2016). Arguably, the most important empirical debate in the literature has been to distinguish periods of contagion, from normal interdependence during the period of changed volatility to periods of stress in the financial system. The literature originated largely with Forbes and Rigobon (2002).

An appealing way of testing for contagion is via changes in correlation between assets or markets. A correlation coefficient is a simple transformation of the links between two markets, scaled by their relative volatility (that is, in the regression of $y_{t}=\beta x_{t}+\varepsilon_{t}$, where $y$ and $x$ are stochastic variables representing different stock market returns, $\beta$ is the ordinary least squares estimates and $\varepsilon_{t}$, the residuals. The correlation coefficient is given by $\rho=\beta \sigma^{x} \sigma^{-y}$ where $\sigma^{x}$ is the variance of $x$ and $\sigma^{y}$ the variance of $y$ ). A simple test of change in transmission between two sample periods is then whether $\rho_{1}=\rho_{2}$, which is essentially a proxy for the underlying test of $\beta_{1}=\beta_{2}$ (where $\rho_{1}$ and $\rho_{2}$ are the correlation coefficients in the two periods, while $\beta_{1}$ and $\beta_{2}$ are the ordinary least squares estimates in the two periods). Forbes and Rigobon (2002) point out that there is a mechanical relationship between increased volatility and an increase in the correlation coefficient between periods. They suggest a scaled version of the correlation coefficient to correct the test. Empirically, this vastly reduces the incidence of contagion identified between the uncorrected and corrected correlation tests. Unfortunately, the Forbes and Rigobon (2002) correction has been shown to be overzealous and results in the underdetection of contagion. This is partly due to the need to accommodate the bounded nature of correlation coefficients in applying $t$ tests to the difference between them via a Fisher correction. Dungey and Zhumabekova (2001) examine the properties and Dungey et al. (2005) examine a correction. But even this relies on unconditional variance estimates for distinct periods. 
Two developments provide some improvement for contagion detection. The first is the implementation of two-sided tests where contagion is associated with statistically significant increases in transmission links (correlation) between assets. Here, no statistically significant changes are labeled interdependence, and evidence of a statistically significant reduction in the transmission between assets (correlation) is labeled decoupling. Decoupling stems from literature that includes Caporin et al. (2018), who show that Portugal and Greece's debt markets during the European debt crisis were less associated with movements in source markets when they were in crisis than during normal times. Evidence of these effects is becoming more pronounced, particularly as studies of financial markets under stress are able to take into account a greater variety of potential links with the greater use of multivariate models and increased processing capacity for higher-order models.

The second development is the use of conditional variance to identify contagion effects and hence control for changes in the relative volatility of the assets under consideration. Contagion tests in the correlation form implicitly rely on the assumption that the relative contribution of idiosyncratic and market shocks remains the same for each asset during periods of stress and calm. Using a decomposition that takes advantage of the conditional variance of the assets, Dungey and Renault (2018) show how the underlying test of changes in transmission (contagion) between markets can accommodate the potential for change in the idiosyncratic volatility for individual assets. This changes the results in a priori unpredictable direction compared with the unconditional test results.

This paper uses the Dungey and Renault (2018) contagion tests and compares the outcomes with the traditional Forbes and Rigobon (2002) uncorrected and corrected tests. We also identify whether each of these tests is consistent with contagion, interdependence, or decoupling, moving beyond the one-sided contagion test common in the correlation test literature.

We consider three aspects of recent developments in the literature on modeling transmissions between markets during periods when turmoil appears and disappears in other markets. We contribute to the literature by investigating how the vulnerability changes within time with specific emphasis on Asia market. We focus on the impact of shocks transmission on Asian markets and, specifically, incorporate the following:

(i) modeling the time-varying contribution of spillovers for Asian markets during and after the global financial crisis;

(ii) testing for abrupt changes in the transmissions of shocks to Asian markets consistent with contagion effects as volatility conditions change in global markets; and

(iii) distinguishing between amplifying and dampening transmissions in spillover linkages, and between contagion, interdependence, and decoupling for abrupt changes.

\section{DETECTING CONTAGION AND VULNERABILITY}

We start by looking at the time-varying nature of the contributions of shocks from the different sources over the sample period using an unconditional analysis to identify spillovers. We then take into account the conditional relationships between markets during different periods in the sample. We use this to identify the extent of change in the propagation of shocks from source markets to target markets in different periods. These two approaches have several advantages over those in the literature. The main one is that the effects of one market on another are signed. That is, not only can we detect whether there is a significant transmission path of unusual shocks between markets and their direction, but we can also determine whether that transmission amplifies or dampens the effects on the recipient market. This aspect is not addressed in most analyses of shock transmission; for 
example, Diebold and Yilmaz (2009, 2014); Billio et al. (2012); and, for contagion, Forbes and Rigobon (2002). The extant literature looks primarily for evidence of significant links (and perhaps their direction) rather than the sign of those links. For policy and investment management purposes, however, the significance, direction, and sign of the links are all relevant. Policy makers and investors want to know whether an event in a source market is likely to affect another market (via significance and direction), and whether that is likely to amplify or dampen volatility or returns (via sign) in the target market. We now introduce the two methodologies: the generalized historical decomposition methodology and the contagion methodology. ${ }^{4}$

\section{A. Spillovers Using the Generalized Historical Decomposition Methodology}

Consider $n$-variable vector of returns from different markets, $R_{t}$, which we consider are related to each other in the normal course of internationally linked financial markets. We apply a standard VAR to the vector of returns. Note that this is the same assumption as lagging the US returns by 1 day in the dataset to time-align the data. The difference the two choices make is in the number of included lags of US returns in the model.

Consequently, we can write

$$
R_{t}=c+\sum_{p=1}^{P} \Phi_{p} R_{t-p}+\varepsilon_{t}
$$

where $P$ is the number of lags, ${ }^{5} \Phi_{p}$ and $c$ are parameters of the model, and $\varepsilon_{t}$ represents reduced form errors. There are many potential problems with modeling daily returns in this manner, including the issue of GARCH and non-normality (for example, Dungey et al. [2015] for the inclusion of GARCH into VAR representations). The problem is one of tractability: accounting for multivariate GARCH greatly reduces the tractability of the model and increases its numerical complexity for estimation. In keeping with the approach of Diebold and Yilmaz (2009, 2014), we put these issues aside for the purposes of computing the spillover and directional spillover indexes proposed here. ${ }^{6}$

Spillovers are measured by the combined effects of the shocks originating in one market on other markets. That is, they represent how effects flow from one market to another net of own-market effects. In the Diebold and Yilmaz approach, the spillover measure is achieved using the forecast error variance decomposition matrix from the VAR at a specified forecast horizon. They obtain a timevarying measure by using VARs estimated from rolling windows of data across the sample. Thus, the Diebold-Yilmaz spillover index involves two ex ante modeling choices-the forecast horizon and the size of the rolling window.

Because all VARs have a moving average form, we can form a standard forecast error variance decomposition, and use this to attribute the contribution of particular shocks to $R_{j}$ to the $H$ step ahead of the generalized forecast error variance of $R_{i}$, (for $i, j=1,2, \ldots, n$, such that $\left.i \neq j\right) \theta_{i j}^{g}(H)$, which is represented by

4 Dungey et al. (2018) give further technical details on the generalized historical decompositions, and Dungey and Renault (2018) on the contagion methodology.

5 The choice of $p$ in the empirical section is based on Akaike information criterion. We use $P=2$.

6 Note that Billio et al. (2012) take the alternative route of prefiltering their data for GARCH properties before looking at links between them. We do not follow this approach because we want to exploit how the relationships between the series move through periods of changing volatility. 


$$
\theta_{i j}^{g}(H)=\frac{V_{j j}^{-1} \sum_{h=0}^{H-1}\left(e_{i}^{\prime} B_{h} V e_{j}\right)^{2}}{\sum_{h=0}^{H-1}\left(e^{\prime}{ }_{i} B_{h} V B^{\prime}{ }_{h} e_{i}\right)}
$$

where, $g$ represents generalized variance decomposition, $H$ is the chosen forecast error variance horizon; $V$ is the variance covariance matrix for the error term, $\varepsilon_{t} ; V_{j j}$ is the standard deviation of the $j$ th error term, $e_{j}$ is the selection vector with 1 as the $j$ th term and 0 elsewhere. The coefficient matrices of $B_{i}$, obey the recursion $B_{i}=\phi_{1} B_{i-1}+\phi_{2} B_{i-2}+\cdots+\phi_{k} B_{i-k}$ with $B_{0}$ an $n \times n$ identity matrix and $B_{i}=0$ for $i<0$. Each entry of the generalized variance decomposition is normalized by the row sum as

$$
w_{i j}=\frac{\theta_{i j}^{g}(H)}{\sum_{j=1}^{n} \theta_{i j}^{g}(H)},
$$

where $\sum_{j=1}^{n} w_{i j}=1$ and $\sum_{i j=1}^{n}=n$. We denote the values defined in (3) as Diebold-Yilmaz weights. In essence, this allows us to determine the proportion of the variance observed in return $i$, due to shocks from return $j$. Diebold-Yilmaz spillover is the combination of all shocks from all the offdiagonal elements in a forecast error variance decomposition. That is, it is composed of all the contributions to forecast error variance that are not due to own shocks. In applications such as Yilmaz (2010), the spillover index between $N$ nodes is represented as

$$
S(H)=100 * \frac{\sum_{i, j=1, i \neq j}^{n} \theta_{i j}^{g}(H)}{N}
$$

The generalized historical decomposition takes the estimated VAR in a slightly different organizational direction. Rather than focusing on the forecast error variance decomposition it instead uses the moving average representation of the VAR to recognize that at any point in time, $t$, a return, $r_{i, t} \in R_{t}$, can be expressed as a sum of all the previous shocks in the system. We can therefore write

$$
r_{i, t}=\text { initial conditions }+\sum_{\tau=0}^{t} \sum_{j=1}^{n} \theta_{i j} \varepsilon_{j, t-\tau}
$$

where initial condition is the starting values in the VAR. For the purposes of our spillover indexes this gives us the ability to propose the same form of the Diebold-Yilmaz spillover index, but with the advantage that the parameters $\theta_{i j}$ are not restricted to being strictly positive, as is the case for the weights from the forecast error variance decomposition, as given in equation (6). Consequently, we can trace a spillover or vulnerability index over time using historical decomposition, and see not only the contributions that shocks from different markets have made to the system but also whether these shocks were amplifying or dampening the transmission from the source market. The disadvantage is that our decomposition is sourced from an unconditional estimate of the system over the sample period, and that it does not directly capture problems that may be associated with changing underlying variance regimes in the data. This is a particular problem for comparing noncrisis and crisis periods. To deal with this, we construct subsample VARs for the same subsamples used in the contagion estimation, which is outlined in the following discussion on the contagion methodology, so that the results are directly comparable across the two methods. 


\section{B. Contagion Methodology}

In a latent factor model representation of the relationship between markets, we might postulate that each return is exposed to both a common factor, $f_{w, t}$, and an idiosyncratic factor, $f_{i, t}$, (or that it is in capital asset pricing model framework with a nondiversifiable and diversifiable risk). So, we are able to write that any individual return at time $t$, denoted $r_{i, t} \in R_{t}$,

$$
r_{i, t}=\beta_{i} f_{w, t}+f_{i, t}
$$

where in matrix form the system is represented by

$$
R_{t}=\mathrm{B} f_{w, t}+F_{t}
$$

and $F_{t}$ is a diagonal matrix which represent the variances. In a capital asset pricing model framework, we invoke a market indicator or "mimicking factor" to represent $f_{w, t}$, and this is usually in the form of market return (often an index or an equally weighted index of constituent assets). That is, the usual formulation of equation (9) will be

$$
r_{i, t}=\beta_{i} r_{0, t}+u_{i, t}
$$

where $r_{0}$ is the asset return of possible source of contagion, $r_{i}$ is the asset return of possible target of contagion, $\beta_{i}$ is identified by the correlation between $r_{i}$ and $r_{0}$, and the idiosyncratic factors are represented by the residuals in equation (8).

The problem of identifying contagion arises when, during different sample periods, we observe changes in the relationships between the variables, specifically changes in $\beta_{i}$ and we want to know the source of those changes. Consider two periods defined as periods of low and high volatility-for convenience we label them $L$ (low volatility) and $H$ (high volatility). In the simplest case we can observe that

$$
\begin{gathered}
r_{i, L}=\beta_{i, L} r_{0, t}+u_{i t}, \\
r_{i, H}=\beta_{i, H} r_{0, t}+u_{i H},
\end{gathered}
$$

where $\beta_{i, L} \neq \beta_{i, H}$ and is identified by the correlation in low and high periods, respectively. The debate is then about why these parameters (or corresponding matrices for a vector of returns) have changed. Initial arguments centered on changes in volatility contributing to changes in correlation and resulting in increased nondiversifiable risk during crisis periods due to $B_{H}>B_{L}$. Forbes and Rigobon (2002), however, showed the mechanical relationship between higher volatility and higher correlation parameters. They concluded that in most cases, the increase in $B_{H}$ in a period of high volatility was mainly due to the interdependence of markets rather than contagion.

Consider for example the correlation between $r_{i}$ and $r_{0}$ in the low and high periods. We know that in the simple form, we are using the correlation coefficient $\rho_{i, L}$ (low period) and $\rho_{i, H}$ (high period) that can be expressed as

$$
\rho_{i, L}=\beta_{i, L} \frac{\sigma_{0, L}}{\sigma_{i, L}}, \rho_{i, H}=\beta_{i, H} \frac{\sigma_{0 H}}{\sigma_{i, H}}
$$


where $\sigma_{i, L}, \sigma_{0, L}, \sigma_{i, H}, \sigma_{0, H}$ are the volatility of returns in both the target and source markets (for both low and high periods), with a corresponding form for $\rho_{i, L}$ and $\rho_{i, H}$. Rearranging this so that the parameters $\beta_{i, L}$ and $\beta_{i, H}$ can be directly compared, we get the Forbes and Rigobon (2002) result that if the increase in volatility in the source market from $\sigma_{0, L}$ to $\sigma_{0, H}$ is not exactly offset by the same rise in the volatility of the target market from $\sigma_{i, L}$ to $\sigma_{i, H}$, then the observed correlation must increase. That is, if the increase in volatility in the source market exceeds the change in volatility in the target market, we will necessarily observe $\rho_{i, H}>\rho_{i, L}$ in a way that is not consistent with contagion as an increase in the transmission of shocks in $\beta_{i}$ between the two periods. This led Forbes and Rigobon (2002) to propose a scaling adjustment to tests of contagion based on correlation. They concluded that most contagion identified in this manner was because of changes in underlying volatility.

The Forbes-Rigobon adjustment has been shown to under reject the null hypothesis of no contagion (Dungey et al. 2005). This is because the change in observed volatility in the target market has two potential sources. The first is the transmission of increased volatility from the source market; that is, the increase in $\sigma_{i}$. The other is due to potential changes in the volatility in the idiosyncratic component (the diversifiable risk) associated with the asset, which we denote $\omega_{i}=\operatorname{var}\left(u_{i}\right)$. Dungey and Renault (2018) provide the proof that the Forbes-Rigobon adjustment will work only where idiosyncratic volatility in the target markets is also unchanged between sample periods; that is, when $\omega_{i, L}=\omega_{i, H}$. Otherwise the test on correlations will tend to overaccept the null of no contagion.

The clearest lesson from the literature on detecting contagion via changes in correlation coefficients is that although it is intuitively appealing, it is also fraught with hazard because of the number of implicit assumptions invoked. The clearest approach is to look directly at the changes in $\beta_{i}$ between periods and, at the same time, being aware that these changes have several sources of volatility influence that need to be distinguished.

Consider that equation (9) and (10) are our approximation of equation (8), where we approximate the common factor with our mimicking return, $r_{0, t}$ and that this can be represented as

$$
f_{w, t}=b r_{0, t}+v_{0, t}
$$

where $\operatorname{var}\left(v_{0, t+1}\right)=\omega_{0}^{2}$ and the correlation between the idiosyncratic component of $f_{w, t}$ and of $r_{i, t}$ is denoted as

$$
\operatorname{cov}\left(u_{i, t+1}, u_{0, t+1}\right)=\omega_{i, 0}
$$

Assuming the shocks to $f_{w, t}$ are independent, we find the unconditional variance of $f_{w, t}$, which is not identified. The return variance of $f_{w, t}$ can be extended by incorporating a constant component. This constant component represents the proportion of the factor variance explained by the mimicking return, that is,

$$
\left.\alpha=\frac{\operatorname{var}\left(f_{w}\right)}{\operatorname{var}\left(r_{0, t+1}\right)}=\frac{\sigma_{w}^{2}}{\sigma_{0}^{2}}, \alpha \in\right] 0,1[
$$

which means that it must be large enough to capture at least part of the variation in the factor. This is done by setting a minimum value on $\alpha$ so that it must allow at least some of the variation to be captured by the common factor in all periods by setting $\alpha=\bar{\alpha}$ at the lower bound that respects this condition. We do this by setting $\bar{\alpha}$ as 1 minus the proportion of the unconditional variance of the 
mimicking asset explained by the minimum conditional variance of that asset over the sample period. That is,

$$
\bar{\alpha}=1-\frac{\min _{1 \ll t \ll T}\left[\operatorname{var}_{t}\left(r_{0 i, t+1}\right)\right]}{\operatorname{var}\left(r_{0, t+1}\right)} .
$$

With these definitions in mind, we can return to the form of equation (8) and note that

$$
\operatorname{cov}\left(f_{i, t} f_{w, t}\right)=\operatorname{cov}\left(r_{i, t+1} r_{0, t+1}\right)=b \sigma_{w}^{2}+\omega_{i, 0} .
$$

To get our expression for the components of $\beta_{i}$ (identified by the correlation between $r_{i}$ and $r_{0}$ ), we recognize the following:

$$
\begin{aligned}
& \beta_{i}=\frac{\operatorname{cov}\left(r_{i, t+1} r_{0, t+1}\right)}{\operatorname{var}\left(r_{0, t+1}\right)}, \\
& \operatorname{var}\left(r_{0, t+1}\right)=\frac{\sigma_{w}^{2}}{\alpha}, \\
& \operatorname{var}\left(r_{0, t+1}\right)=\frac{\omega_{0}^{2}}{1-\alpha},
\end{aligned}
$$

where equation (17) comes from the definition of correlation, the second comes from equation (14), and the third from the definition of the variance structure of the common factor, taking into account the scaling parameter $\alpha_{i}$. So, to obtain an expression for $\beta_{i}$ we scale $\operatorname{cov}\left(r_{i, t+1} r_{0, t+1}\right)$ by $\operatorname{var}\left(r_{0, t+1}\right)$, the second term by the equivalent value of equation (17), and the third term by the value equation (18) leaving the final expression for $\beta_{i}$ as

$$
\beta_{i}=\alpha_{i} b_{i}+\left(1-\alpha_{i}\right) \frac{\omega_{i 0}}{\omega_{0}^{2}}
$$

This expression shows that the parameter of interest in transmitting the shocks from the source asset to the target asset can be decomposed into two components. The first is the common transmission effect; the second is the effect of the changing conditional variances between the idiosyncratic shocks in the common factor and the idiosyncratic factor. A test for a change in $\beta_{i}$ that does not acknowledge this may mistake changes in relative volatility for structural changes in the transmission of shocks.

We are interested in tests of whether there is a change in $b_{i}$ between periods. We omit, however, the source proposed by Sewraj, Gebka, and Anderson (2018), which adds a trend termspecifying in equation (9), for example, that $\beta_{i}=\gamma_{i, 0}+\gamma_{i, 1} t$-to capture the changing integration of the target market with the source market because of increased global integration over time. We use relatively short sample periods, and the evidence in Sewraj, Gebka, and Anderson (2018) suggests that the effects, while statistically significant, are economically very small (even over more than 2 decades of weekly data) and not evident in the crisis period.

Although we have illustrated this problem for a single asset related to a common mimicking factor, the model is easily extended to a vector of assets in relation to a single mimicking factor, and with some degree of greater complexity to the possibility of more than one mimicking factor, analogous to a multifactor capital asset pricing model (Dungey and Renault 2018). Dungey and 
Renault (2018) established a method for identifying these contagion effects using conditional variance. The method is simple to use and offers insights into the source of changes in the transmission matrix over subsamples.

\section{Estimation Strategy}

Testing for statistical changes in the parameter $b_{i}$ for assets can be achieved using generalized method of moments and conditional second moment conditions. We know that the instrumented unconditional covariance between one asset $r_{i}$ and another $r_{j}$ (with the same mimicking portfolio asset in place for both, $r_{0}$ ) will be constant in our framework (Dungey and Renault 2018), but the intuition follows from equation (1)

$$
E\left[z_{t} r_{j, t+1}\left(r_{i, t+1}-b_{i} r_{0, t+1}\right)\right]=c_{i j}
$$

where $z_{t}$ is a vector of instruments used to capture conditional heteroskedasticity. It is $(n+2)$ dimensional vector containing a constant and squared returns $r_{j, t}{ }^{2}, I=0,1, \ldots, n$. This implies that equation (21) will have unconditional moment restrictions. The moment restriction can be represented in linear regression model as

$$
\left(r_{t+1} \otimes z_{t}\right) r_{t+1}=b_{i}\left(r_{t+1} \otimes z_{t}\right) r_{0, t+1}+\left[I_{n+1} \otimes z_{t}\right] c_{i .}+\varepsilon_{i, t+1}
$$

where $r_{t+1}=\left(r_{j, t+1}\right)_{0 \leq j \leq n}, I_{n+1}$ the identity matrix of dimension $(n+1), c_{i .}=\left(c_{i j}\right)_{0 \leq j \leq n}$ and $\varepsilon_{i, t+1}$ is a $(n+1)(n+2)$-dimensional martingale difference sequence.

We also know that the unconditional covariance between $r_{i}$ and $r_{0}$ is constant

$$
E\left[r_{0, t+1}\left(r_{i, t+1}-\alpha_{i} b_{i} r_{0, t+1}\right)\right]=\omega_{i j}
$$

where $\alpha_{i}$ is to be chosen such that it is constrained by the fact that the volatility must be sufficiently large to capture at least part of the variation in the factor, with the assumption that one or two-factor model or its characterization through moment conditions in equations (21) and (23) are well specified. Estimation of these parameters can be implemented using a generalized method of moments. ${ }^{7}$

These two sets of moment conditions across multiple assets are demonstrated here with a single mimicking portfolio that provides sufficient identification to estimate the parameters of interest, specifically $b_{i}$ for different sample periods. We can then test the null hypothesis of $b_{i, L}=b_{i, H}$ as a more clearly specified test for the presence of contagion than of either $\beta_{i, L}=\beta_{i, H}$, which may be contaminated by changing idiosyncratic variances, or $\rho_{i, L}=\rho_{i, H}$, which may be contaminated by changes in both idiosyncratic variances and the relative variance of the assets over time.

\section{DATA AND STYLIZED FACTS}

The dataset includes 12 Asian daily equity market indexes (in local currencies), and the equity market index of Australia and the US from January 2003 to December 2017, as listed in Table 1. These are daily (closing) equity market indexes.

\footnotetext{
7 See Dungey and Renault 2018 for more details.
} 
Table 1: Markets in the Sample

\begin{tabular}{lllc}
\hline Market & Abbreviation & Market & Abbreviation \\
\hline Australia & AUS & Philippines & PHI \\
India & IND & Republic of Korea & KOR \\
Indonesia & INO & Singapore & SIN \\
Japan & JPN & Sri Lanka & SRI \\
Hong Kong, China & HKG & Taipei,China & TAP \\
Malaysia & MAL & Thailand & THA \\
People's Republic of China & URC & United States & USA
\end{tabular}

Source: Thomson Reuters Datastream.

Figure 1: Equity Market Indexes, 2003-2017

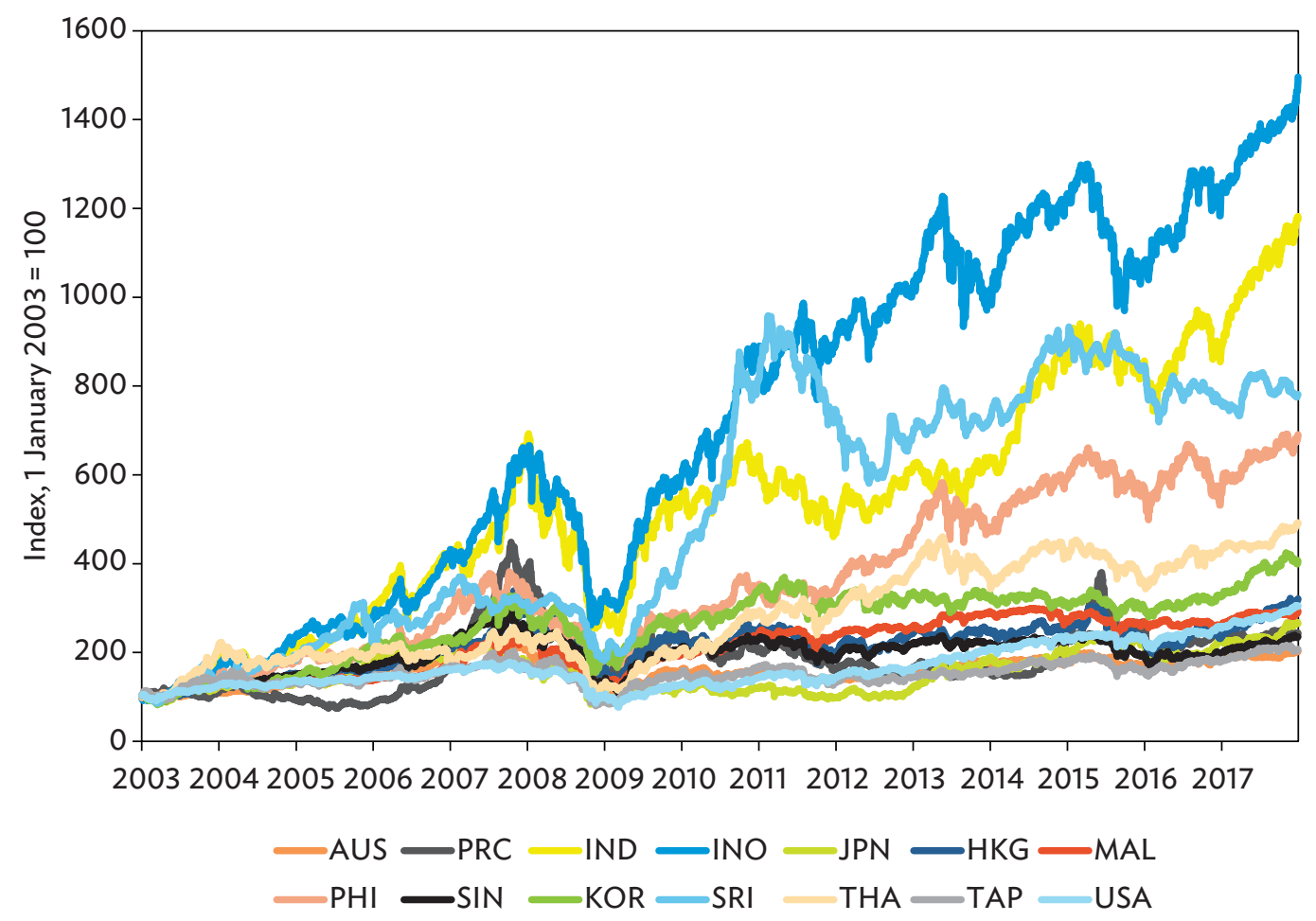

AUS = Australia; HKG = Hong Kong, China; IND = India; INO = Indonesia; JPN = Japan; KOR = Republic of Korea; MAL = Malaysia; $\mathrm{PHI}=$ Philippines; PRC = People's Republic of China; SIN = Singapore; SRI = Sri Lanka; TAP = Taipei,China; THA = Thailand; USA = United States.

Source: Authors. 
Figure 1 plots the equity market indexes for each market scaled such that the first observation is 100 in each series. Unit root tests reveal the usual characteristics of stationary returns in each series. The analysis is conducted using demeaned returns; this is because the mean is usually extremely close to 0 and, since we are focused on decompositions, this assumption is innocuous. We use the data with its recorded closing time date. The US data is nonoverlapping with Asian market timing, so that events in the US on a given date cannot provoke a reaction in an Asian market until the following day. For this reason, contemporaneous US returns are accommodated in the spillovers. And in the contagion analysis, we lag the US returns by 1 day (with sensitivity tests against contemporaneous returns).

\section{RESULTS AND ANALYSIS}

Our choice of studying returns rather than volatility is guided by the findings in the literature that returns have less volatile spillover effects (Yilmaz 2010), and that means have been found to transmit most information in the Asian markets (Beirne et al. 2010).

Table 2 shows the four subsample periods in our empirical analysis. The first is the pre-global financial crisis (GFC) period, from January 2003 until the bankruptcy of Lehman Brothers in midSeptember 2008. The second is from then to the end of March 2010-the GFC period. This may be regarded as overly long compared with some other analyses, and the literature is indeed mixed on whether it divides the US recovery from mid-2009 into a separate period. Dungey et al. (2015) discuss dating the crisis. The third period is the European debt crisis, which we designate as starting from the beginning of the International Monetary Fund's program in Greece in April 2010 until the end of December 2013-at that point, only Ireland and Portugal still had to finalize their recovery from the support packages implemented during the crisis, and they both achieved this in 2014 . $^{8}$ The fourth period covers the most recent data from January 2014 to the end of the sample on 29 December 2017. The total number of observations in the whole sample is 3,913. Just over $30 \%$ of the observations are found in the run-up to the GFC period, and approximately one-quarter in each of the European debt crisis period and the postcrisis periods. The GFC period is the shortest, covering 6 months from the collapse of Lehman Brothers; this period contains just under 10\% (403) of the total observations. Thus, each subsample has a reasonable number of observations for tractable estimation and is in line with existing demarcations of the sample periods.

Table 2: Phases of the Sample

\begin{tabular}{lllc}
\hline Phase & \multicolumn{1}{c}{ Period } & \multicolumn{1}{c}{ Representing } & $\begin{array}{c}\text { Number of } \\
\text { Observations }\end{array}$ \\
\hline Pre-GFC & 1 January 2003-14 September 2008 & Lead up to the global financial crisis & 1,488 \\
GFC & 15 September 2008-31 March 2010 & Global financial crisis & 403 \\
EDC & 1 April 2010-30 December 2013 & European debt crisis & 979 \\
Recent & 1 January 2014-29 December 2017 & Most recent period & 1,043 \\
\hline
\end{tabular}

$\mathrm{EDC}=$ European debt crisis, GFC = global financial crisis. Source: Authors.

Table 3 shows the descriptive statistics for each equity market return for each country across the different subsamples.

8 The financial crisis in Cyprus was also resolved in 2014 and was relatively minor compared with the conditions experienced earlier in the European debt crisis period. 


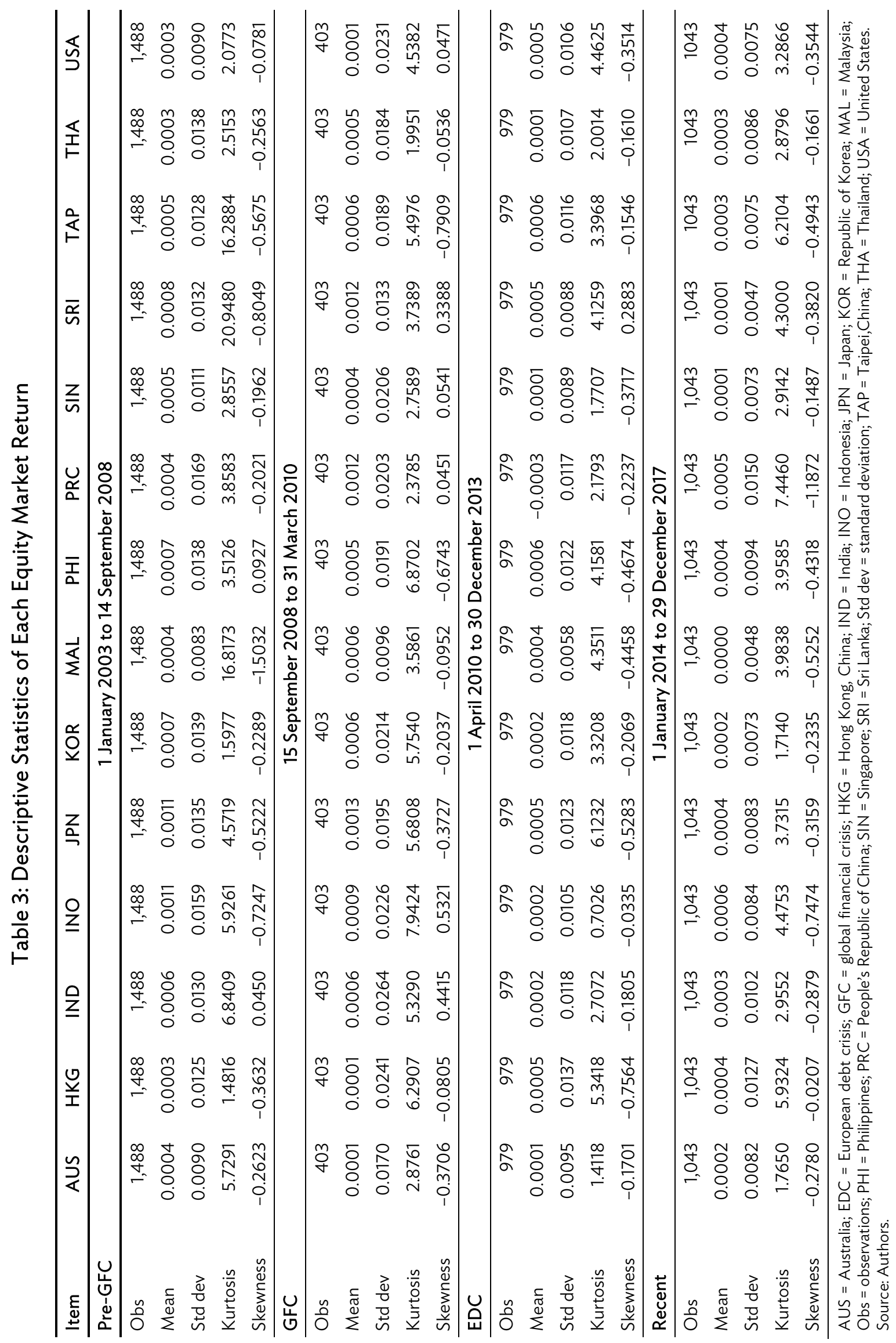




\section{A. Evidence for Spillovers}

Table 4 shows the average historical decomposition of shocks to the observed returns of each country in the sample for the whole period. The rows represent the recipient markets for shocks spread from source countries, which are shown in each column. The cell values are the average of the historical decomposition shocks in the whole sample. The shocks have different magnitude and are distinguished by sign. Negative numbers represent a reduction in returns as a result of the shock; positive shocks represent an increase in returns. Observations in bold represent the largest shocks distributed across different markets.

The US receives more shocks than it transmits. This is common because each market is exposed to shocks from many markets-and distributes its own shocks to many markets. The US receives positive shocks from Asian countries, on average increasing its return, while it also transmits shocks - though with less magnitude-to Asian countries. These outcomes are in general consistent with the US being the safe haven market when international stress occurs. US markets benefit from flight to safety and familiarity, and benefit from the hypothesis of Kaminsky and Reinhart (2003) that the US operates as a central market that redistributes shocks received from peripheral markets to other markets.

Unlike the US, which receives positive shocks, the PRC receives negative shocks from most of the other markets, although the magnitude of these shocks is low. Indonesia and Japan receive the largest positive shocks from other Asian markets, but they transmit smaller shocks to other Asian markets.

We now consider how the transmission of shocks changes over time by examining the four periods. The results in Tables 5, 6, 7, and 8 clearly show that the transmission of shocks from different markets change in each phase.

During the GFC period, the US becomes the recipient of larger positive shocks from Asian markets compared with the pre-GFC period. The US also transmits more shocks to Asian markets than it absorbs in the GFC period. The magnitude of shocks it receives drops in the GFC period compared with the pre-GFC period. This result suggests that Asian markets were less involved in spreading shocks to the US during the GFC period. Figure 2 shows these results. Panel (a) shows the estimated receipt of shocks by a market; panel (b) shows the transmission of shocks from a market. The spillover effect for each market during each phase is given by separate columns. The figure clearly shows that in the pre-GFC period, the average spillover effect that the market was transmitting to others in the system was roughly similar, mainly in the range of 0.1-0.2 with the exception of an almost neutral transmission from Sri Lanka and the US. The average effect was only negative in the US, at a very small $-0.0063$.

Compared with later periods, the extent of the shocks during the pre-GFC period was small, although with more heterogeneity than with the transmissions in this period. Australia and India were among the countries that receive on average negative effects on their returns as spillovers from the rest of the markets. Indonesia; Hong Kong, China; and Thailand received return-enhancing spillovers. The other markets are between these two alternatives, although the range is not high. 


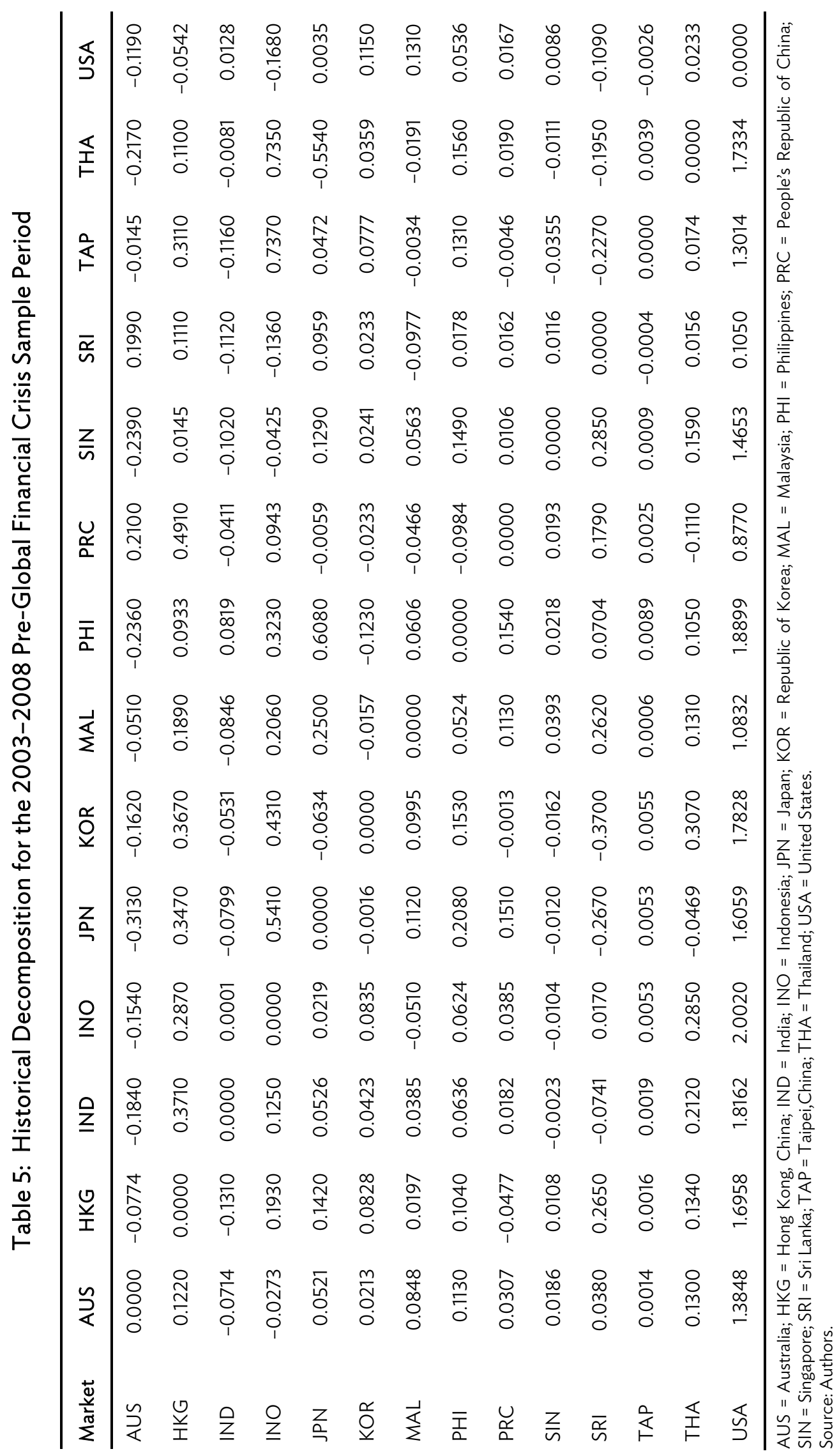


Figure 2: Average Shocks Reception and Transmission by Period and Market
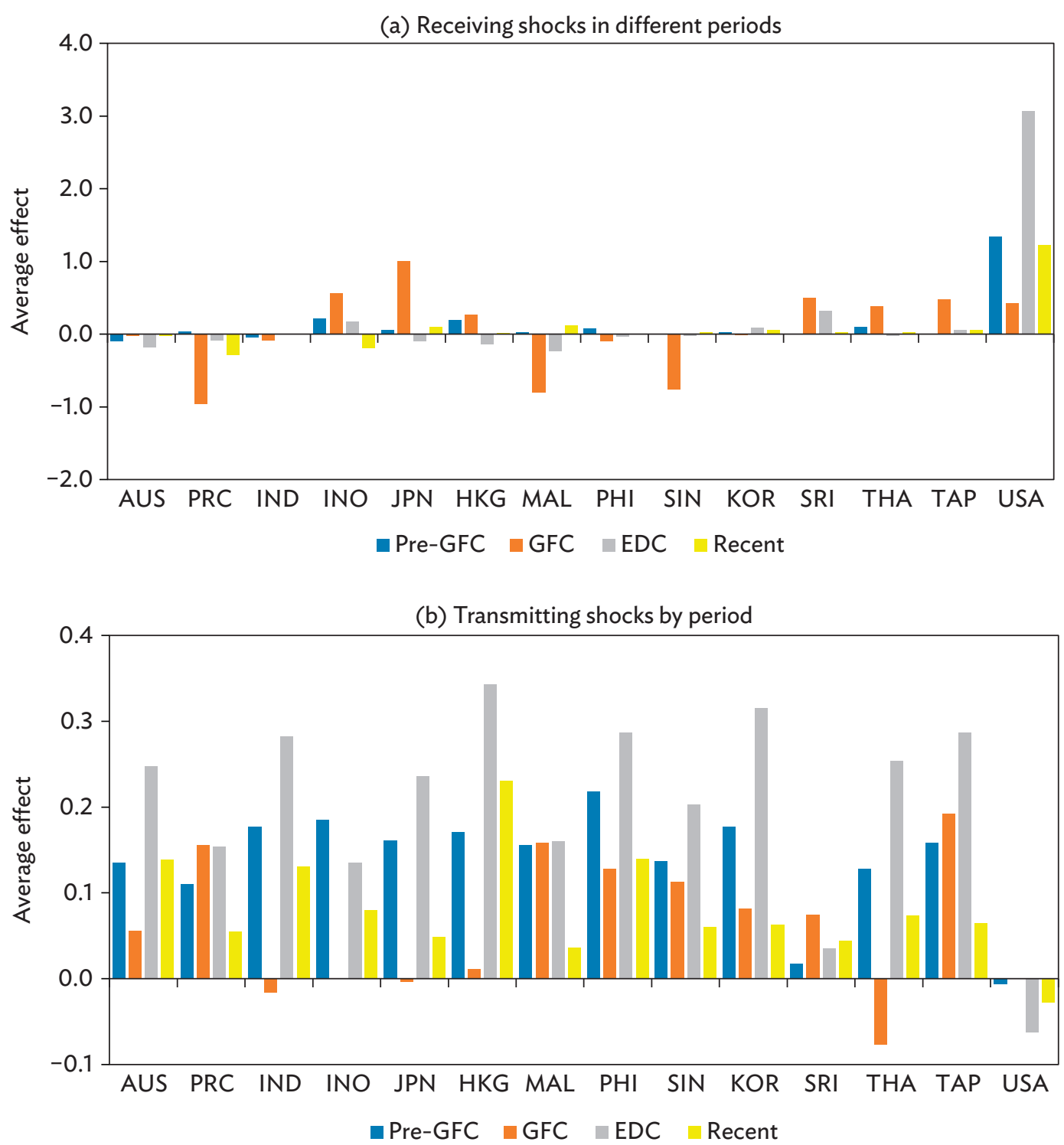

AUS = Australia EDC = European debt crisis; GFC = global financial crisis; HKG = Hong Kong, China; IND = India; INO = Indonesia; $\mathrm{JPN}=$ Japan; $\mathrm{KOR}=$ Republic of Korea; $\mathrm{MAL}=$ Malaysia; $\mathrm{PHI}=$ Philippines; $\mathrm{PRC}=$ People's Republic of China; SIN = Singapore; SRI = Sri Lanka; TAP = Taipei,China; THA = Thailand; USA = United States.

Source: Authors. 
During the GFC period the transmission of shocks from source markets generally declined from the pre-GFC period. But while there is some slight evidence that the transmission of these shocks increased returns in other markets via spillovers, even less evidence suggests they had reduced returns, except for spillovers from Thailand. Table 6 shows this is mainly through spillovers with the PRC, Malaysia, and Singapore.

Spillover effects from shocks received during the GFC period are vastly increased in the preGFC period, with the scale of the effects up to 4 times higher. Most of the sample markets continue to receive on average the same sign effect of shocks in both periods, although Malaysia and the PRC receive opposite average effects. For Japan, these are spillovers that increase their returns, which is consistent with the flight to quality, safety, and familiarity in the region. The spillover effects for the PRC are strongly negative, reflecting the expected decline in the country's economic expansion in response to a weaker global economy. Malaysia and Singapore, also open and export-dependent economies, experience negative spillovers in the GFC period. The US gets some positive spillovers because of the flight to safety and leverage effects. The Republic of Korea experiences relatively little change, with the average effect of spillovers that it receives remaining neutral in both periods.

The European debt crisis period is a complete contrast to the pre-GFC and GFC periods, with the scale of spillovers into and out of markets being similar, and almost all markets experiencing positive spillovers (Table 7). That is, spillovers result in higher returns in these markets, and spillovers from Asian markets result in higher returns elsewhere. This may reflect that the origins of the crisis were in Europe and the debt markets of Asia were seen as more robust, thereby providing an alternative investment opportunity during the European debt crisis period. ${ }^{9}$ In contrast, spillovers to and from the US are negative. In other words, spillovers from the US were reducing returns in Asia, reflecting uncertainty in world markets, and spillovers from Asia were reducing returns in the US.

The most recent period shows a return to conditions more similar to the pre-GFC period in its transmission effects. These are, if anything, slightly smaller than in the other periods, but produce positive returns in Asian markets. The exception again is the US, where spillovers from the country tend on average to reduce returns in other markets, with a larger effect than in the pre-GFC period of -0.0275 .

Table 8 shows that transmissions to Indonesia and the PRC are important components of this overall result. In contrast, the spillovers that other markets receive from others during the recent period in general have little effect on returns for each country. The scale of shocks to the US is considerably larger than for other markets and these effects are positive, implying that spillovers from other markers are on average increasing US returns. Most markets receive on average negligible spillovers from other markets. The exceptions are Indonesia, the PRC, and the US. Indonesia and the PRC seem to be intertwined in a form of feedback where spillovers between them (evident in Table 8) are mutually reinforcing lower returns. ${ }^{10}$ The spillover effects on the US are substantially larger than in the other periods, and primarily reflect combinations of Indonesia and PRC spillovers, although with offset from Malaysia also playing a role.

9 See, for example, the analysis of credit default swaps data in Dungey, Harvey, and Volkov (2018).

10 See for example the literature on diabolical loops. 


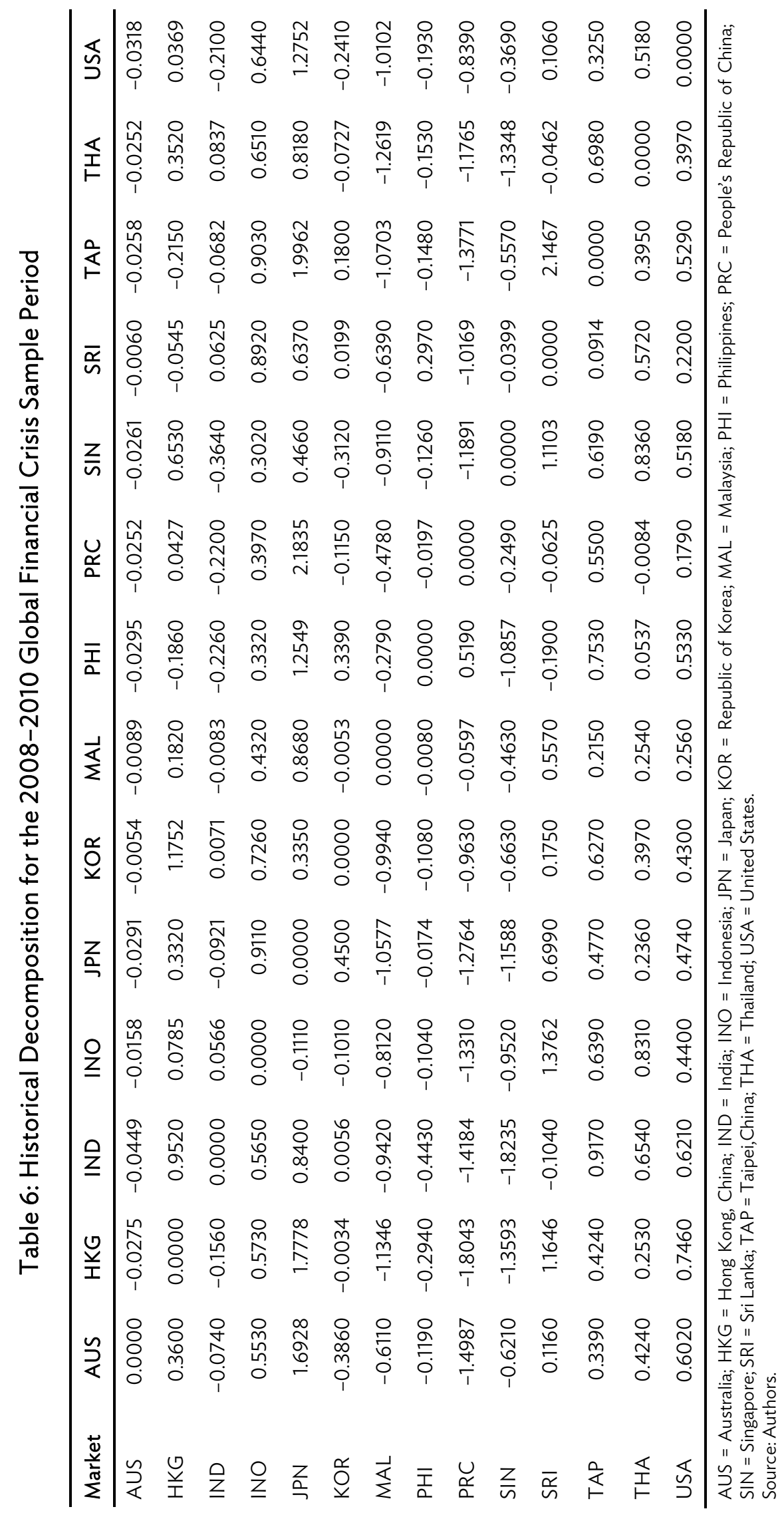




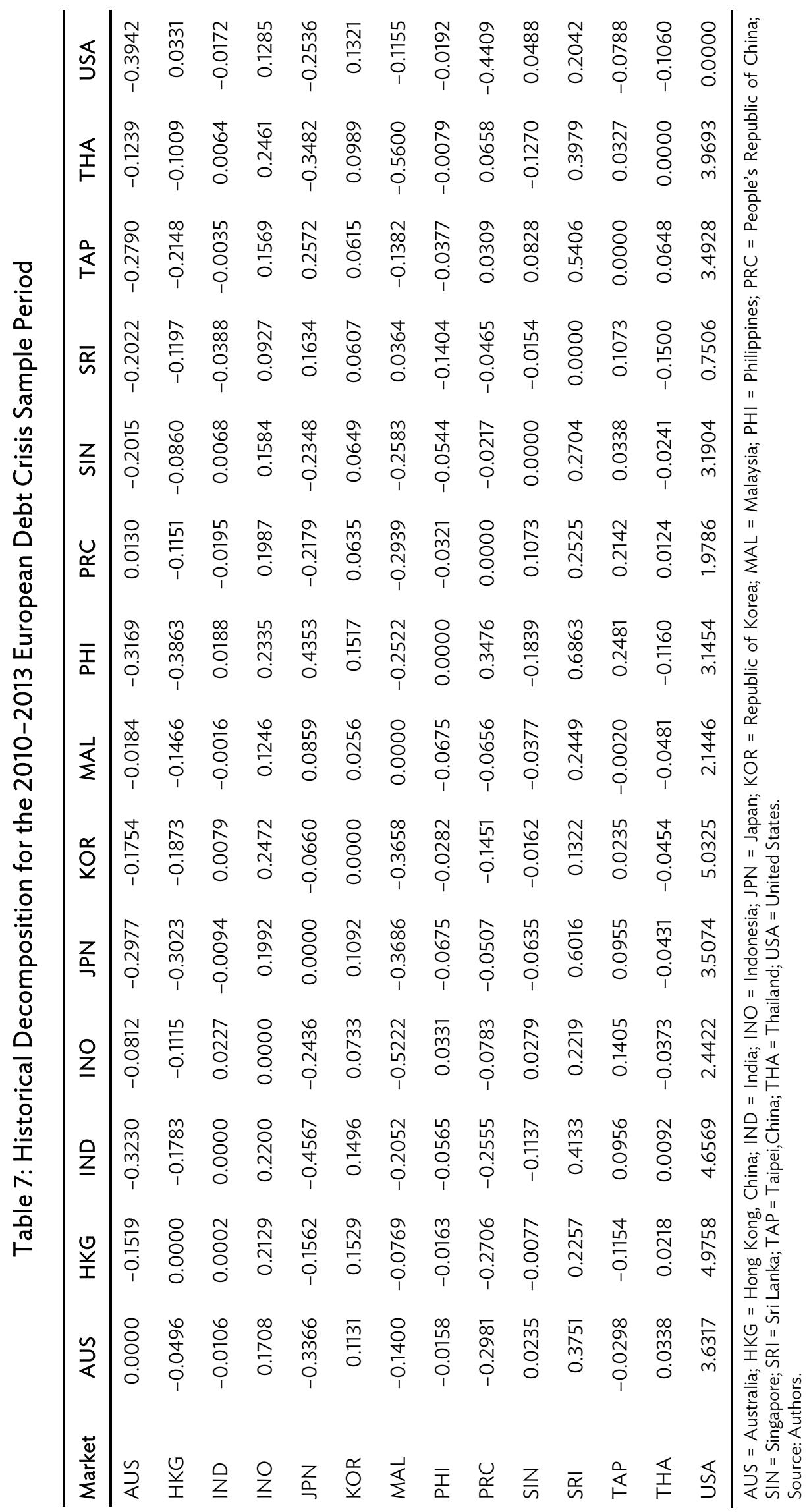




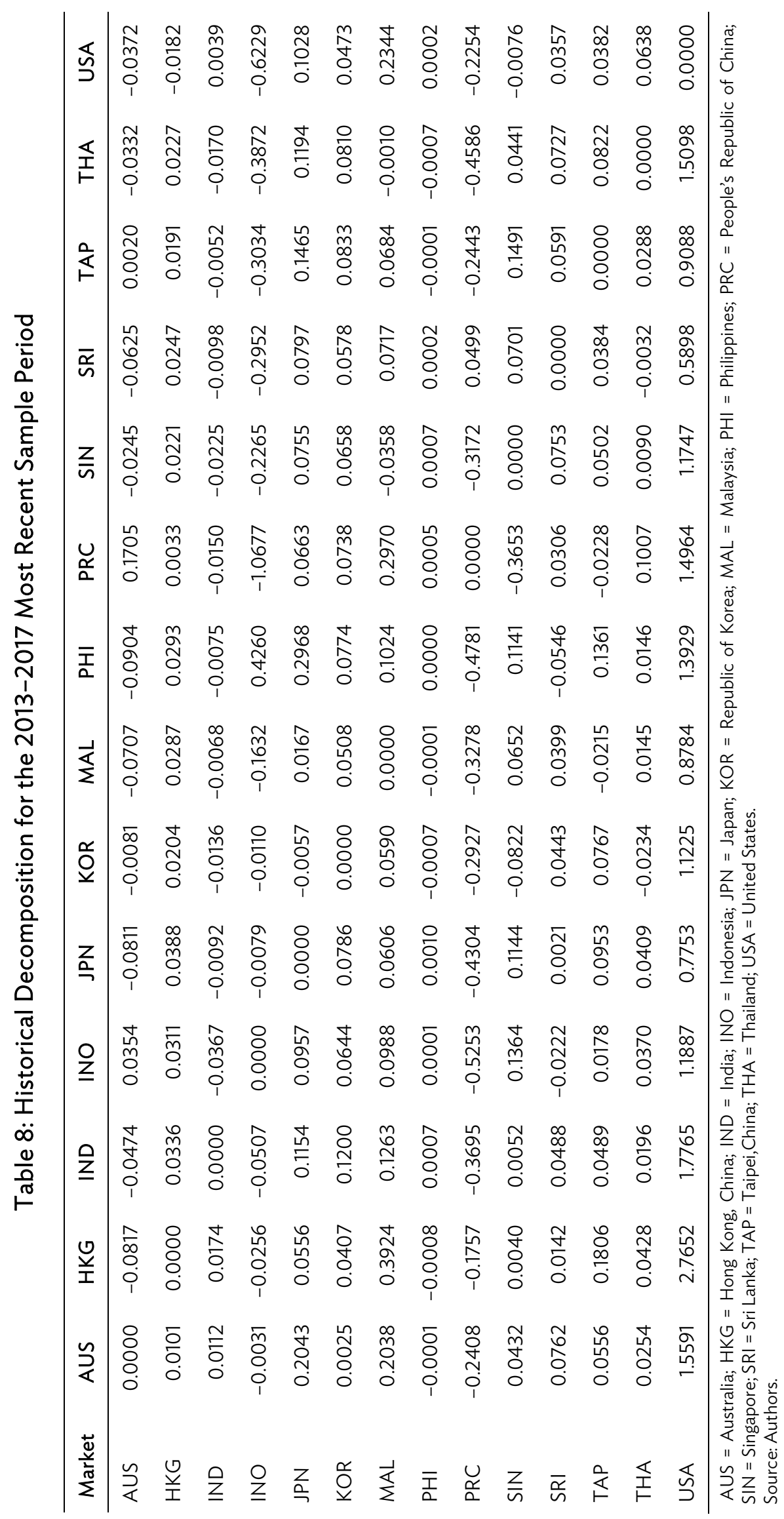


The important though different roles that the PRC and the US play in the spillovers to and from Asian markets is very evident in this analysis-and because of this we look more closely at the spillovers originating from these markets. Table 9 shows the total contributions of spillovers to and from the PRC and the US to and from the other markets over the four periods. This allows for a preliminary analysis of the extent of change in the transmissions between these markets before formally testing for contagion in section $V$.B.

The results of Table 9 are plotted in Figure 3. The scales on panels (a) and (b) in the figure for the transmission of spillovers are substantially smaller than those for receiving spillovers, as explained earlier. The transmissions in panels (a) and (b) show that the spillovers from the PRC and the US are larger in the GFC period than in other periods, particularly in the pre-GFC period. In both cases, the largest spillovers during the GFC period from both these sources were to Japan, indicating its importance in the region. During the European debt crisis period, spillovers are calmer, although there is evidence that some begin to, on net, switch direction so that Hong Kong, China; Japan; and Malaysia, for example, have the opposite total spillover effect in this period than during the GFC period.

Table 9: Summary of Spillovers from and to the People's Republic of China and the United States by Other Markets

\begin{tabular}{|c|c|c|c|c|c|}
\hline \multicolumn{6}{|c|}{ (a) From the PRC to other markets } \\
\hline From & To & Pre-GFC & GFC & EDC & Recent \\
\hline & AUS & 0.2100 & -0.0252 & 0.0130 & 0.1705 \\
\hline & HKG & 0.4910 & 0.0427 & -0.1151 & 0.0033 \\
\hline & IND & -0.0411 & -0.2200 & -0.0195 & -0.0150 \\
\hline & INO & 0.0943 & 0.3970 & 0.1987 & -1.0677 \\
\hline & JPN & -0.0059 & 2.1835 & -0.2179 & 0.0663 \\
\hline & KOR & -0.0233 & -0.1150 & 0.0635 & 0.0738 \\
\hline \multirow[t]{7}{*}{ PRC } & MAL & -0.0466 & -0.4780 & -0.2939 & 0.2970 \\
\hline & $\mathrm{PHI}$ & -0.0984 & -0.0197 & -0.0321 & 0.0005 \\
\hline & $\mathrm{SIN}$ & 0.0193 & -0.2490 & 0.1073 & -0.3653 \\
\hline & SRI & 0.1790 & -0.0625 & 0.2525 & 0.0306 \\
\hline & TAP & 0.0025 & 0.5500 & 0.2142 & -0.0228 \\
\hline & THA & -0.1110 & -0.0084 & 0.0124 & 0.1007 \\
\hline & USA & 0.8770 & 0.1790 & 1.9786 & 1.4964 \\
\hline \multicolumn{6}{|c|}{ (b) From the USA to other markets } \\
\hline From & To & Pre-GFC & GFC & EDC & Recent \\
\hline \multirow{9}{*}{ USA } & AUS & -0.1190 & -0.0318 & -0.3942 & -0.0372 \\
\hline & HKG & -0.0542 & 0.0369 & 0.0331 & -0.0182 \\
\hline & IND & 0.0128 & -0.2100 & -0.0172 & 0.0039 \\
\hline & INO & -0.1680 & 0.6440 & 0.1285 & -0.6229 \\
\hline & $J P N$ & 0.0035 & 1.2752 & -0.2536 & 0.1028 \\
\hline & KOR & 0.1150 & -0.2410 & 0.1321 & 0.0473 \\
\hline & MAL & 0.1310 & -1.0102 & -0.1155 & 0.2344 \\
\hline & $\mathrm{PHI}$ & 0.0536 & -0.1930 & -0.0192 & 0.0002 \\
\hline & PRC & 0.0167 & -0.8390 & -0.4409 & -0.2254 \\
\hline
\end{tabular}


24 | ADB Economics Working Paper Series No. 583

Table 9 continued

\begin{tabular}{|c|c|c|c|c|c|}
\hline \multicolumn{6}{|c|}{ (b) From the USA to other markets } \\
\hline From & To & Pre-GFC & GFC & EDC & Recent \\
\hline & SIN & 0.0086 & -0.3690 & 0.0488 & -0.0076 \\
\hline & SRI & -0.1090 & 0.1060 & 0.2042 & 0.0357 \\
\hline & TAP & -0.0026 & 0.3250 & -0.0788 & 0.0382 \\
\hline & THA & 0.0233 & 0.5180 & -0.1060 & 0.0638 \\
\hline \multicolumn{6}{|c|}{ (c) From other markets to the PRC } \\
\hline From & To & Pre-GFC & GFC & EDC & Recent \\
\hline AUS & & 0.0307 & -1.4987 & -0.2981 & -0.2408 \\
\hline HKG & & -0.0477 & -1.8043 & -0.2706 & -0.1757 \\
\hline IND & & 0.0182 & -1.4184 & -0.2555 & -0.3695 \\
\hline INO & & 0.0385 & -1.3310 & -0.0783 & -0.5253 \\
\hline JPN & & 0.1510 & -1.2764 & -0.0507 & -0.4304 \\
\hline KOR & & -0.0013 & -0.9630 & -0.1451 & -0.2927 \\
\hline MAL & PRC & 0.1130 & -0.0597 & -0.0656 & -0.3278 \\
\hline $\mathrm{PHI}$ & & 0.1540 & 0.5190 & 0.3476 & -0.4781 \\
\hline SIN & & 0.0106 & -1.1891 & -0.0217 & -0.3172 \\
\hline SRI & & 0.0162 & -1.0169 & -0.0465 & 0.0499 \\
\hline TAP & & -0.0046 & -1.3771 & 0.0309 & -0.2443 \\
\hline THA & & 0.0190 & -1.1765 & 0.0658 & -0.4586 \\
\hline USA & & 0.0167 & -0.8390 & -0.4409 & -0.2254 \\
\hline \multicolumn{6}{|c|}{ (d) From other markets to the USA } \\
\hline From & To & Pre-GFC & GFC & EDC & Recent \\
\hline AUS & & 1.3848 & 0.6020 & 3.6317 & 1.5591 \\
\hline HKG & & 1.6958 & 0.7460 & 4.9758 & 2.7652 \\
\hline IND & & 1.8162 & 0.6210 & 4.6569 & 1.7765 \\
\hline INO & & 2.0020 & 0.4400 & 2.4422 & 1.1887 \\
\hline JPN & & 1.6059 & 0.4740 & 3.5074 & 0.7753 \\
\hline KOR & & 1.7828 & 0.4300 & 5.0325 & 1.1225 \\
\hline MAL & USA & 1.0832 & 0.2560 & 2.1446 & 0.8784 \\
\hline $\mathrm{PHI}$ & & 1.8899 & 0.5330 & 3.1454 & 1.3929 \\
\hline PRC & & 0.8770 & 0.1790 & 1.9786 & 1.4964 \\
\hline SIN & & 1.4653 & 0.5180 & 3.1904 & 1.1747 \\
\hline SRI & & 0.1050 & 0.2200 & 0.7506 & 0.5898 \\
\hline TAP & & 1.3014 & 0.5290 & 3.4928 & 0.9088 \\
\hline THA & & 1.7334 & 0.3970 & 3.9693 & 1.5098 \\
\hline
\end{tabular}

AUS = Australia; EDC = European debt crisis; GFC = global financial crisis; HKG = Hong Kong, China; IND = India; INO = Indonesia; JPN = Japan; KOR = Republic of Korea; MAL = Malaysia; PHI = Philippines; PRC = People's Republic of China; SIN = Singapore; SRI = Sri Lanka; TAP = Taipei, China; THA = Thailand USA = United States .

Source: Authors. 
Figure 3: Receiving and Transmitting Spillovers to and from the United States and the People's Republic of China
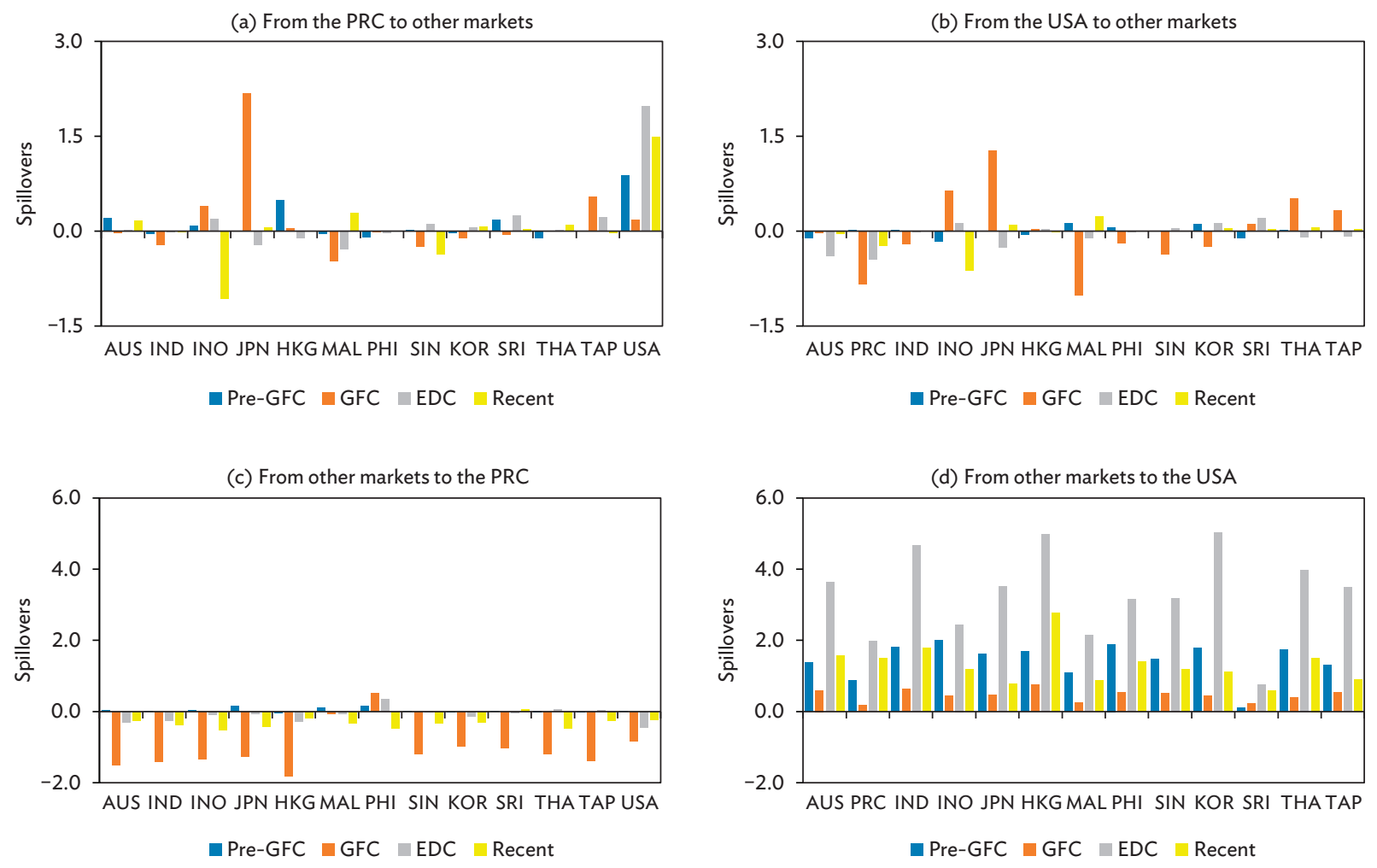

AUS = Australia; EDC = European debt crisis; GFC = global financial crisis; HKG = Hong Kong, China; IND = India; INO = Indonesia; JPN = Japan; $\mathrm{KOR}=$ Republic of Korea; $\mathrm{MAL}=$ Malaysia; $\mathrm{PHI}=$ Philippines; $\mathrm{PRC}=$ People's Republic of China; SIN = Singapore; SRI = Sri Lanka; TAP = Taipei,China; THA = Thailand; USA = United States .

Source: Authors

The analysis of spillovers from other markets to the PRC and the US in panels (c) and (d) of Figure 3 show stark differences in scale and direction. The spillovers to the PRC from other markets are predominantly negative, particularly during the GFC period, but are on a smaller absolute scale than those to the US. The spillovers received by the US are positive for each of the four periods (recalling this is an average effect for the period) and greatest during the European debt crisis period. The spillovers to the US reduced-but remained positive-during the GFC period compared with the preGFC period for many markets, a result consistent with the reduced attractiveness of US markets during this crisis period. During the European debt crisis period, when US assets became much more attractive than those of crisis-hit Europe, the spillovers to the US from Asian markets increased substantially. In the most recent period, the extent of average spillovers is reduced, but remains higher than the pre-GFC period.

The clearest result from the analysis of Table 9 and Figure 3 is that the spillovers from the PRC to the US are negative but shrinking across the four periods, while the spillovers from the US to the PRC are positive and arguably growing. This is consistent with a narrative that the US and the PRC are becoming more internationally intertwined, and that improvements in both economies can be 
expected to flow to each other. The results for the most recent period indicate that there is less evidence of fear of PRC spillovers leading to negative implications for the US economy, pointing to a more developed market relationship. Arslanalp et al. (2016) show that the effect of shocks from the PRC on the US is increasing. Given the dominant role that transmissions from the PRC and the US play in our analysis of spillovers, we now look at the more abrupt changes in transmission by examining the evidence for contagion across these markets and subsamples.

Figure 4, panel (a), shows the Diebold-Yilmaz spillover index for the network of returns produced using a 200-day moving window. Because the corresponding generalized historical decomposition (GHD) figure for returns is uninformative, we instead provide the GHD for the

Figure 4: Spillover Index Based on Diebold-Yilmaz and Generalized Historical Decomposition
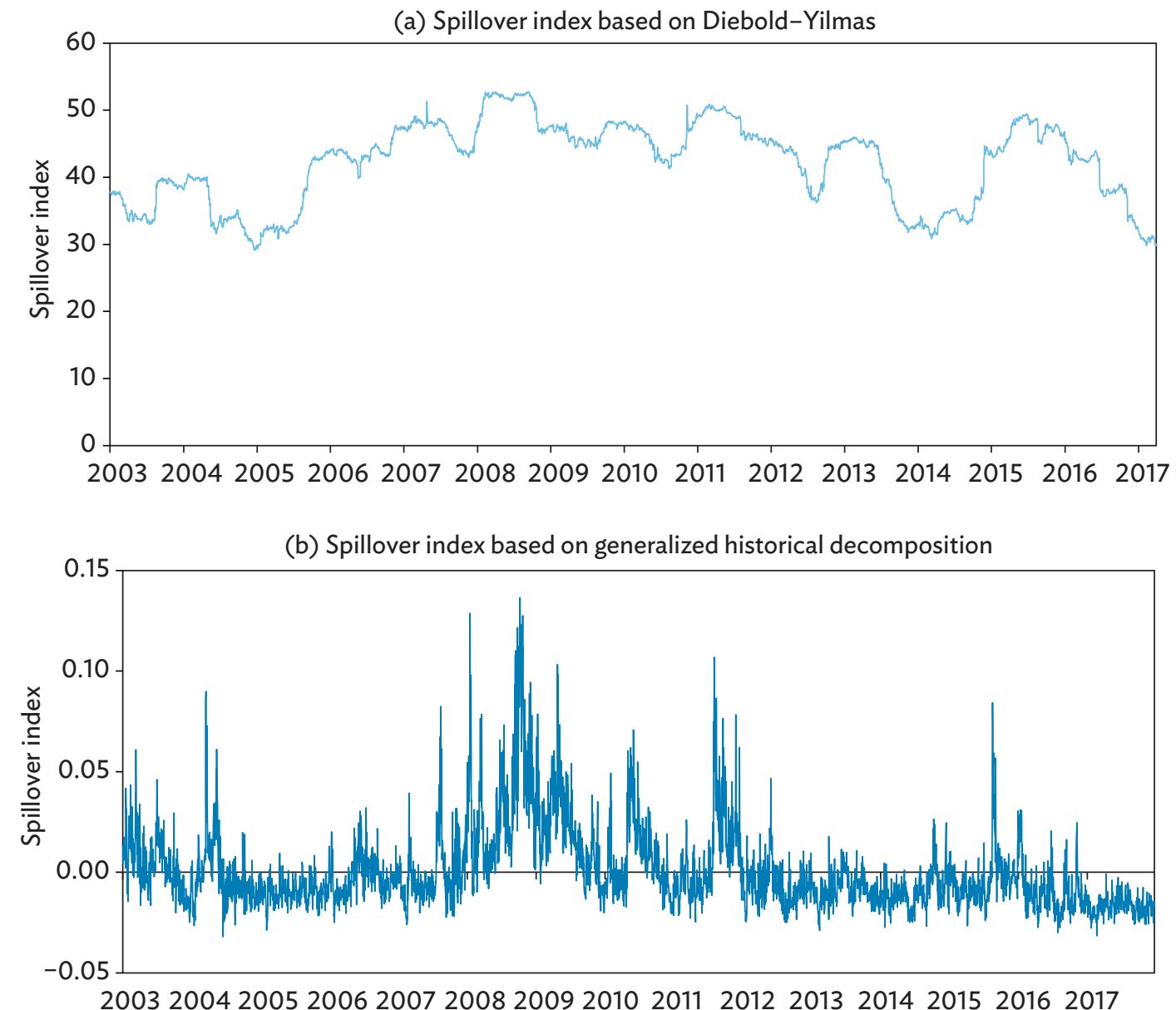
volatility network in panel (b). The results show that the spillover index for the entire network ranged from 30\% to 50\% over the 2003-2017 sample period, beginning and ending near the minimum of the range. The Diebold-Yilmaz spillover index shows a substantial increase in spillovers between markets from 2005. This peaked in the second half of 2008 and is consistent with the timing of the collapse of Lehman Brothers and the associated turmoil. The index calms somewhat after the GFC period, with some increase in spillovers associated with the European debt crisis period. In the most recent period, however, the index fell in 2014, rose over 2015, and dropped rapidly in 2017. A prominent feature of the index is the role of the choice of window length. Here, the sensitivity to the choice is readily apparent in Figure 4 as critical observations drop in and out of the rolling sample.

The GHD spillover index in panel (b) of Figure 4 shows distinct periods where transmissions were contributing to higher or lower volatility in the entire financial system. Observations below the 0 line indicate cases where transmissions in the network dampened volatility; that is, the network was robust in the sense that shocks were dampened by its structure. Positive observations indicate instances where the network's structure amplified the effects of the shocks. Figure 4 shows that from mid-2004 to mid-2007 the network primarily acted to dampen the shocks; that is, it displayed a robust structure. There was a slight period of amplification in late 2006 , but this is dwarfed by subsequent high-amplification effects in the network from mid-2007 to mid-2009. These are the largest absolute values in Figure 4 and indicate that the shocks during this period were causing a substantial amplification in the network's volatility transmission. The network became fragile in the sense of Acemoglu, Ozdaglar, and Tahbaz-Salehi (2015) and Haldane (2009). The results concur with the analysis of Dungey, Harvey, and Volkov (2018), where the fragility of a network of global sovereign and financial institution credit default swaps increases to the stage where almost the entire network can be expected to default in response to a tail shock. The GHD spillover index shows that the amplification effect calms down somewhat in 2009, before flaring again during the Greek debt crisis in 2010 and the European debt crisis during 2011-2012.

From late 2012 to 2015 the network returns to a more robust structure, where its effects dampen the impact of shocks. Some abrupt interruptions to the GHD spillover index during 20152016 indicate short, sharp periods of amplification in the network. These are linked to the PRC; for example, August 2016 saw changes to the exchange rate regime and $8 \%$ wiped off the value of the country's stock market in Black Monday. Arslanalp et al. (2016) document the extreme movements in the PRC equity market and examine the strong comovement of Asian markets with the PRC on 11 August 2015 and 4 January 2016. Global markets were rocked again by the unexpected outcome of a vote in the United Kingdom in June 2016 to leave the European Union and the subsequent political turmoil across the global markets. Although political uncertainty continued to affect major markets over the rest of 2016, it did not trigger the same level of network fragility. The network was robust again by 2017 , when shocks were no longer being amplified by the network structure.

\section{B. Evidence for Contagion}

For completeness, we provide the results of the uncorrected and Forbes and Rigobon (2002) corrected contagion tests for each period preceding the subsequent period. That is, whether there is contagion (a statistically significant rise in correlation), interdependence (no significant change), or decoupling (a statistically significant fall in correlation) from one period to the next." Table 10 shows

1 Contagion and decoupling refer to the distinct and abrupt positive and negative changes in the transmission of shocks between markets after controlling for what would be expected by normal spillover effects. That is, they are transmissions that would not have been expected ex ante based on existing historical relationships. 
the results for transmissions from the PRC and the US as source markets for each period. The usual Forbes-Rigobon style results are evident: without the correction for changing variance, the correlation tests reject the null of no contagion almost always. But after the correction, the prevailing evidence is for interdependence or decoupling. Note that the original Forbes-Rigobon approach did not distinguish decoupling; instead, only a one-sided test was done for a rise in correlation as contagion. Later research extended this to two-sided tests and, more recently, research including Caporin et al. (2018) has labeled the reduced correlation outcome as decoupling. Table 10 shows how difficult it can be to reconcile the evidence from different contagion-based testing. Tests must be conducted with a thorough understanding of which compromises are being made in the procedure to achieve identification and empirical tractability. The arguments presented in this paper's discussion on detecting contagion and vulnerability examined the reasons for preferring the approach in Dungey and Renault (2018) for using conditional correlations to those based on unconditional correlations from Forbes and Rigobon (2002), both with and without corrections.

\section{Table 10: United States and the People's Republic of China Results Using Forbes-Rigobon Uncorrected and Corrected Tests, and Dungey-Renault Test}

\begin{tabular}{|c|c|c|c|c|c|c|c|c|c|c|c|c|c|c|c|c|c|c|}
\hline \multirow[b]{3}{*}{ Market } & \multicolumn{9}{|c|}{ Originating from the United States } & \multicolumn{9}{|c|}{ Originating from the People's Republic of China } \\
\hline & \multicolumn{3}{|c|}{ Pre-GFC to GFC } & \multicolumn{3}{|c|}{ GFC to EDC } & \multicolumn{3}{|c|}{ EDC to recent } & \multicolumn{3}{|c|}{ Pre-GFC to GFC } & \multicolumn{3}{|c|}{ GFC to EDC } & \multicolumn{3}{|c|}{ EDC to recent } \\
\hline & FRU & FRC & DR & FRU & FRC & DR & FRU & FRC & DR & FRU & FRC & DR & FRU & FRC & DR & FRU & FRC & DR \\
\hline AUS & $\mathrm{D}$ & I & $\mathrm{D}$ & C & C & $\mathrm{D}$ & $\mathrm{D}$ & I & $\mathrm{D}$ & $\mathrm{C}$ & C & C & C & C & $\mathrm{C}$ & $\mathrm{D}$ & $\mathrm{D}$ & $\mathrm{D}$ \\
\hline HKG & I & I & $D$ & I & C & $D$ & I & C & $C$ & $C$ & C & $D$ & I & C & $C$ & $\mathrm{D}$ & $D$ & $D$ \\
\hline IND & $\mathrm{D}$ & 1 & $\mathrm{D}$ & 1 & $C$ & $\mathrm{D}$ & 1 & $C$ & $\mathrm{D}$ & $C$ & $C$ & $C$ & I & $C$ & $C$ & I & $\mathrm{D}$ & $D$ \\
\hline JPN & D & I & $\mathrm{D}$ & 1 & C & D & 1 & 1 & $\mathrm{D}$ & $C$ & C & $\mathrm{D}$ & 1 & C & $C$ & D & D & D \\
\hline KOR & $D$ & I & $\mathrm{D}$ & I & C & C & $\mathrm{D}$ & I & $D$ & $C$ & C & $D$ & I & C & $C$ & $D$ & $D$ & $D$ \\
\hline MAL & D & I & $\mathrm{D}$ & D & I & D & I & C & $D$ & $C$ & C & $D$ & I & C & $C$ & I & D & $D$ \\
\hline $\mathrm{PHI}$ & D & I & D & I & I & $\mathrm{D}$ & C & C & $D$ & $C$ & I & $\mathrm{D}$ & 1 & C & $C$ & D & D & D \\
\hline PRC & 1 & 1 & $C$ & 1 & $C$ & $C$ & 1 & $C$ & $C$ & 0 & 0 & 0 & 0 & 0 & 0 & 0 & 0 & 0 \\
\hline SIN & I & I & $\mathrm{D}$ & I & I & $\mathrm{D}$ & I & I & $\mathrm{D}$ & $C$ & C & $C$ & D & I & $\mathrm{D}$ & I & I & D \\
\hline SRI & $\mathrm{D}$ & 1 & $C$ & 1 & $C$ & $C$ & 1 & 1 & $\mathrm{D}$ & $C$ & $C$ & $D$ & $I$ & $C$ & $C$ & $\mathrm{D}$ & $\mathrm{D}$ & $\mathrm{D}$ \\
\hline TAP & $\mathrm{D}$ & I & $\mathrm{D}$ & $D$ & I & $D$ & I & C & $\mathrm{D}$ & $C$ & C & $D$ & I & C & $C$ & D & $\mathrm{D}$ & $D$ \\
\hline THA & I & 1 & $\mathrm{D}$ & 1 & I & $\mathrm{D}$ & I & I & $C$ & I & I & $C$ & I & 1 & $C$ & C & I & $\mathrm{D}$ \\
\hline USA & 0 & 0 & 0 & 0 & 0 & 0 & 0 & 0 & 0 & I & 1 & $\mathrm{D}$ & 1 & $C$ & $C$ & 1 & 1 & $C$ \\
\hline
\end{tabular}

AUS = Australia; $C=$ contagion; $D=$ decoupling; $D R=$ Dungey-Renault $E D C=$ European debt crisis; $F R C=$ Forbes - Rigobon corrected; $F R U=$ Forbes Rigobon uncorrected; GFC = global financial crisis; HKG = Hong Kong, China; I = interdependence; IND = India; JPN = Japan; KOR = Republic of Korea; MAL = Malaysia; PHI = Philippines; PRC = People's Republic of China; SIN = Singapore; $\mathrm{SRI}=$ Sri Lanka; TAP = Taipei,China; THA = Thailand; USA = United States.

Notes: 0 values represent no detection to itself. Results in bold represent the scenario in which all the contagion tests results come to the same conclusion.

Source: Authors.

Table 11 presents the evidence for contagion from the conditional correlation tests of Dungey and Renault (2018) using the US market as the mimicking factor during each of the four periods. We did a Ghysels-Hall test for the structural change between the adjacent periods, and a Hall test for the 
stability of parameters between the periods. The individual results are not reported because, in each case, the null of no change was rejected at standard significance levels. ${ }^{12}$

\section{Table 11: Estimates of $b$ for Each Subperiod with Mimicking Factor Given by the United States Market}

\begin{tabular}{|c|c|c|c|c|}
\hline Market & Pre-GFC & GFC & EDC & Recent \\
\hline AUS & 2.066 & 1.402 & 1.483 & 0.173 \\
\hline HKG & 2.965 & 1.759 & 1.944 & 1.095 \\
\hline IND & 3.817 & 0.866 & 1.055 & 0.759 \\
\hline INO & 4.416 & 1.133 & 1.618 & 0.102 \\
\hline JPN & 3.664 & 1.195 & 1.072 & 2.060 \\
\hline KOR & 5.129 & 0.927 & 2.620 & 0.372 \\
\hline MAL & 4.094 & 0.650 & 1.323 & 0.250 \\
\hline $\mathrm{PHI}$ & 4.068 & 1.674 & 1.759 & 0.578 \\
\hline PRC & 0.485 & 1.209 & 0.786 & 3.053 \\
\hline SIN & 3.750 & 0.609 & 1.488 & 0.258 \\
\hline SRI & -0.500 & 0.747 & 0.275 & 0.609 \\
\hline TAP & 3.964 & 0.961 & 1.601 & 0.145 \\
\hline THA & 3.044 & 0.130 & 1.795 & 0.497 \\
\hline
\end{tabular}

Panels (a) and (b) in Figure 5 arrange the estimated $b$ parameter by market and sample period. It is clear from these charts in Figure 5 that the loading on the mimicking factor in the precrisis period is generally greater than at any other part of the sample period. For most markets, the part of the relationship that is stable and not dependent on the relative volatilities of the individual and mimicking markets is higher in the pre-GFC period, and lower in the other periods. In fact, for nine of the 12 markets, the value of the $b$ parameter drops markedly from the pre-GFC to the GFC period, and increases again-though only slightly-in the European debt crisis period before falling in the most recent period. Consequently, what we observe is a decoupling of these markets from the US market over the four periods. From the GFC period to the European debt crisis period, there is some evidence of recoupling (after the GFC), but it is limited and short-lived in size compared with the extent of the decoupling. This is consistent with the evidence in Kim, Kim, and Lee (2015), who find that the contagion effect of the US financial crisis on Asian economies was detectable but short-lived.

12 Additional results for Tables 11 and 12 can be requested from mardi.dungey@utas.edu.au. 
Figure 5: Structural Transmission Parameter to and from the People's Republic of China and the United States
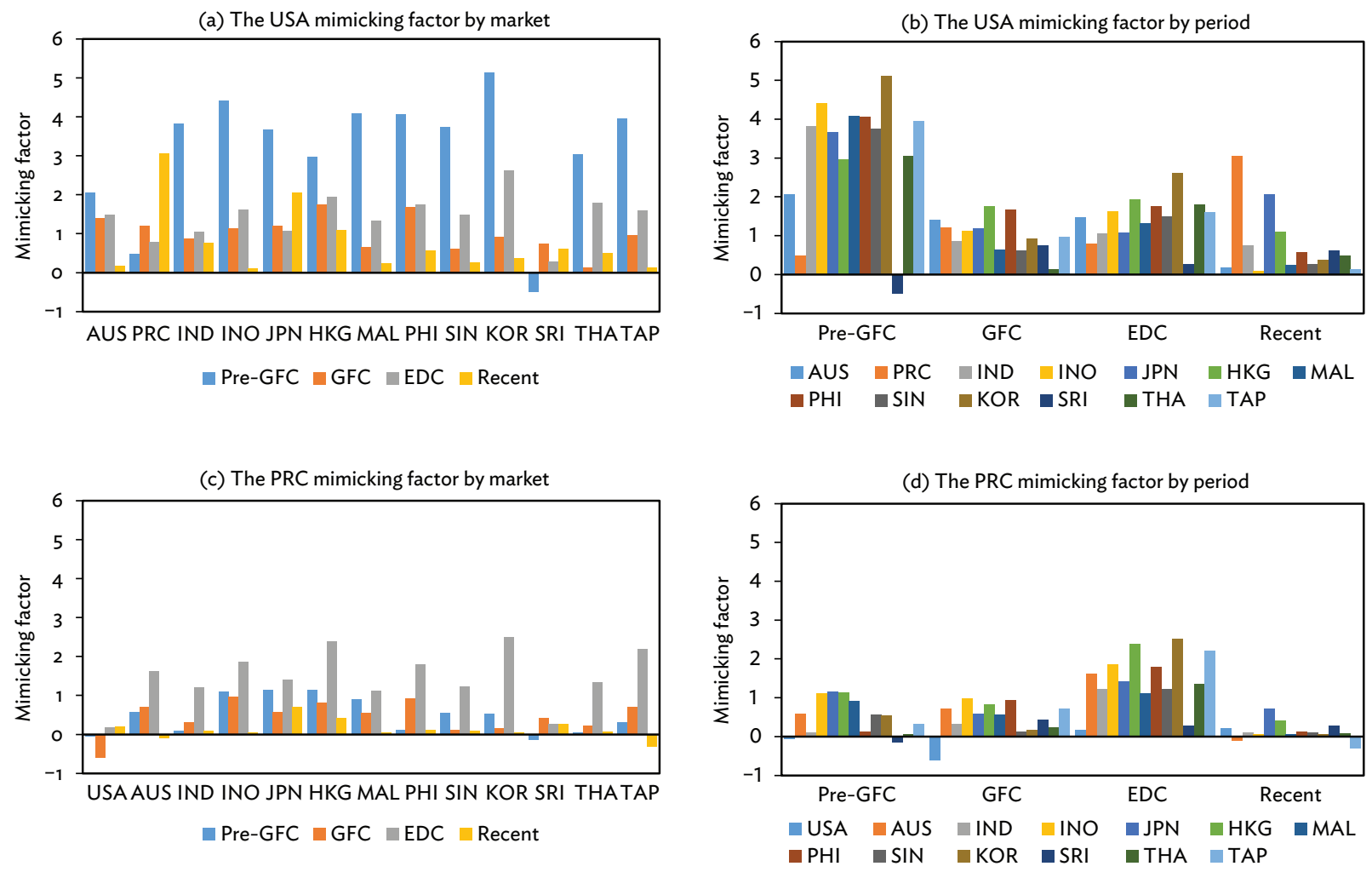

AUS = Australia; $E D C=$ European debt crisis; GFC = global financial crisis; HKG = Hong Kong, China; IND = India; INO = Indonesia; $\mathrm{JPN}=$ Japan; $\mathrm{KOR}=$ Republic of Korea; $\mathrm{MAL}=$ Malaysia; $\mathrm{PHI}=$ Philippines; $\mathrm{PRC}=$ People's Republic of China; $\mathrm{SIN}=$ Singapore; SRI = Sri Lanka; TAP = Taipei, China; THA = Thailand; USA = United States.

Source: Authors.

A few other countries-notably Japan, the PRC, Sri Lanka, and Thailand-display different patterns in their relationship with the US mimicking factor. Sri Lanka is the only market to show a negative relationship with the mimicking factor in the pre-GFC period and in the sample as a whole. This could relate to the civil war that Sri Lanka was grappling with at that time, effectively outweighing external financial market events. The occurrence of the GFC period results in a substantial increase in the estimated $b$ parameter for Sri Lanka indicating substantial contagion. From the GFC period, however, the relationship between the Sri Lankan market and the US mimicking factor returns to the steady decoupling pattern observed in most of the other markets. Thailand differs from the other markets in that it experiences a substantial decoupling from the pre-GFC to the GFC period. After recoupling during the European debt crisis period, Thailand decouples but remains more connected to the US mimicking factor than it was during the GFC period. This is unusual relative to the other markets. 
In Japan's case, the market decoupled from the US mimicking factor during the GFC and the European debt crisis periods, which is consistent with the resilience of Japanese markets during these periods of stress. ${ }^{13}$ In the most recent period, however, Japan recoupled with the US market. This relationship is not as strong as it was in the pre-GFC period, but it is more pronounced than in the intervening periods - and it has the second highest parameter value for the most recent period. The PRC has the largest relationship with the US mimicking factor in the most recent period. Unlike the other markets, the relationship between the PRC and the US markets increased over the entire sample period, albeit with a slight disruption in the European debt crisis period. That is, a formal test for contagion shows an increased correlation between the pre-GFC and GFC periods, and the European debt crisis and most recent periods, both of which are consistent with contagion. The PRC has become more sensitive to shocks emanating from the US mimicking factor in the most recent period.

The analysis so far is consistent with the emerging importance of the PRC as a major financial market for Asia. Because of the increasing influence of the PRC, we now consider the test results when using the country as the mimicking factor of world conditions. In other words, what evidence is there of contagion from market conditions to other Asian countries when the PRC represents the behavior of the global factor? The resulting $b$ parameter estimates are shown in Table 12 and panels (c) and (d) in Figure 5. The results show that using the PRC as the mimicking factor does not result in loadings that are as large as using the US as the mimicking factor. This is not surprising given the role of the US in the world, and it indicates that the country is a better indicator of the common conditions faced by these markets, which is consistent with much of the literature. But it also indicates that the nature of the relationship with the mimicking factor defined by PRC markets has altered over time (Yilmaz 2010).

The relationship of most of the 12 economies with the PRC mimicking factor was highest during the European debt crisis period; this is consistent with the evidence that there was contagionrepresented by a significant change in the $b$ parameter-from the GFC period to this period emanating from the PRC market. The interesting aspect of this is that the correlation increase was not necessarily a "bad" outcome for many markets, but provided an avenue of alternative financial leadership and investment opportunity during a period of turmoil in developed markets. As far as we are aware, this feature has not been noted before. Here, we have an instance where the propagation of shocks from one market source (with the PRC as the mimicking factor) to individual markets increases in a statistically significant way. This is consistent with the definition of contagion, but would not be viewed as necessarily harmful in this application.

We now explore the possibility that the PRC market is not mimicking the crisis-originating part of the market, but should instead be considered as a diversification opportunity. Here, there are two potentially offsetting effects: a turmoil factor for developed markets represented by the US market and an opportunistic alternative for investment funds in the Asian region. This may represent a market that is better understood as having two countering forces. A similar argument has been made for the role of Greece and Germany in the European debt crisis, where Greece represents the problem of the crisis countries, and Germany for the countries that experienced demand via flight to quality (Caporin et al. 2018; Dungey and Renault 2018). A similar situation occurred when Mexico joined the North American Free Trade Agreement. Rigobon (2002) notes that Mexico's market changed its behavior from being clearly aligned with Latin American markets to behaving more in line with North American markets.

13 See Botman, de Carvalho Filho, and Lam (2013) for evidence on the Japanese markets acting as a safe haven. 
Table 12: Estimates of $b$ for Each Subperiod with Mimicking Factor Given by the People's Republic of China Market

\begin{tabular}{lcccc}
\hline Market & Pre-GFC & GFC & EDC & Recent \\
\hline AUS & 0.583 & 0.712 & 1.624 & -0.093 \\
HKG & 1.140 & 0.815 & 2.383 & 0.413 \\
IND & 0.105 & 0.314 & 1.208 & 0.107 \\
INO & 1.108 & 0.979 & 1.860 & 0.047 \\
JPN & 1.148 & 0.584 & 1.409 & 0.711 \\
KOR & 0.532 & 0.163 & 2.498 & 0.060 \\
MAL & 0.900 & 0.564 & 1.116 & 0.045 \\
PHI & 0.124 & 0.936 & 1.795 & 0.126 \\
SIN & 0.547 & 0.115 & 1.227 & 0.091 \\
SRI & -0.140 & 0.430 & 0.271 & 0.266 \\
TAP & 0.309 & 0.711 & 2.200 & -0.307 \\
THA & 0.057 & 0.220 & 1.340 & 0.069 \\
USA & -0.061 & -0.595 & 0.177 & 0.203 \\
\hline AUS & & Austas & & . \\
\hline
\end{tabular}

AUS = Australia; $E D C=$ European debt crisis; GFC = global financial crisis; HKG = Hong Kong, China; IND = India; INO = Indonesia; JPN = Japan; KOR = Republic of Korea; MAL = Malaysia; PHI = Philippines; SIN = Singapore; SRI = Sri Lanka; TAP = Taipei, China; THA = Thailand; USA = United States.

Notes: In each case, the estimates are statistically significant at the $1 \%$ level and are statistically different for each market between periods. The estimates of $b$ are obtained from equation (12).

Source: Authors.

To examine this hypothesis more closely, we respecify the conditional correlation model to take into account the possibility of two distinct sources of market information, with the PRC and the US markets providing the mimicking factors. This represents a generalization of the model given for contagion in the discussion on detecting contagion and vulnerability in section III, where

$$
r_{i, t}=\beta_{i, 1} f_{w 1, t}+\beta_{i, 2} f_{w 2, t}+f_{i, t}
$$

With two common factors and the associated propagation parameters can be expressed as

$$
\begin{aligned}
& \beta_{i 1}=\alpha_{1} b_{i, 1}+\left(1-\alpha_{1}\right) \frac{\omega_{i, 01}}{\omega_{0,1}^{2}}, \\
& \beta_{i 2}=\alpha_{2} b_{i, 2}+\left(1-\alpha_{2}\right) \frac{\omega_{i, 02}}{\omega_{0,2}^{2}} .
\end{aligned}
$$

The tests of interest are the stability of the parameters $b_{i, 1}$ and $b_{i, 2}$ over the different subsamples, where both are estimated in a joint specification. ${ }^{14}$ This specification has the distinct advantage of dealing with multiple sources of contagion at the same time, which is not typically accessible in the standard Forbes-Rigobon correlation tests, though it can be encompassed in other approaches. When using this model, we found the parameterization was not supported by the data. Because the PRC returns are themselves subject to large effects from the US, the independence of the

14 See Dungey and Renault (2018) for further details on a multivariate implementation. 
two factors is compromised in the specification. We therefore conclude that the two-factor specification based on the PRC and the US as the two mimicking factors is not sufficiently empirically supported in the data.

\section{IMPLICATIONS}

The results of testing for changing spillovers and the presence of contagion effects between the four periods strongly support the finding that the network between Asian equity markets changed over 2003-2017. This confirms the results already established with many other methods in the literature.

Several proposals have been made for the driving forces of changing financial market networks. The most common are trade and financial linkages, primarily through international banking, private and public debt ownership, and related areas. There is some evidence that growing international trade is associated with increasing financial integration. Elekdag, Rungcharoenkitkul, and Wu (2012) and Aizenman, Jinjarak, and Park (2015), for example, both use a type of capital asset pricing model to show how the estimated beta of Asian markets is increasing, and that increase is positively associated with growing trade. Arslanalp et al. (2016) find that increasing spillovers from the PRC to other Asian markets are related to trade linkages. But Avdjiev et al. (2018) show that trade effects can be offset by the impact of financial flows in their study on the impact of the US dollar's appreciation on emerging market capital flows. An appreciating US dollar results in lower cross-border bank flows for emerging economies, so that despite improved export prospects, the portfolio channel of transmission can dominate to the extent that it worsens economic growth prospects. Thus, the foundations of the trade channel of transmission are more complex than they first appear, and it is not clear that equity market spillovers can be expected to mirror trade spillovers.

Recent research has investigated the effects of cooperation versus self-directed policy outcomes. These coordination effects have been found to be small in the monetary policy literature. Agénor et al. (2017), however, applied a similar approach to macroprudential policies. They constructed a stylized dynamic stochastic general equilibrium model to examine how spillovers in financial markets can affect countries experiencing financial frictions calibrated to the problem of the benefits of coordination between emerging and advanced economies when viewed through a coreperiphery lens. They found that substantial gains can come from coordinating macroprudential policy responses across countries, but that these gains are correlated with both the size of the economies and the degree of financial friction.

We consider the simple correlation of our spillover results with trade measured as the average annual trade volume in US dollars (from the United Nations Comtrade statistics) and to the size of an economy, using gross domestic product (GDP) per capita. ${ }^{15}$ We find that the correlation between incoming spillovers and GDP per capita is positive at 0.1335. But GDP per capita and outward spillovers are correlated at -0.0170 . That is, as an economy increases in size, the spillovers it transmits have a progressively more dampening effect on other markets. This aligns with the center and periphery style of analyses, where the larger core developed markets receive more shocks than perpetrators (Kaminsky and Reinhart 2002), although we emphasize that these results are weak. We also consider the relationship of GDP per capita to absolute spillovers (|Receipts| + |Transmissions|) and find a correlation of 0.1728 . Thus, our evidence provides only slight support for the hypothesis in Agénor et al. (2017) that spillovers and the size of an economy are positively related. The correlation of the different spillover measures with trade measured as either imports, exports, the sum of imports and

15 Converted with purchasing power parity from the International Monetary Fund's database. https://www.imf.org/en/Data. 
exports, and net trade show that receiving spillovers is correlated with imports. Here, the correlation coefficient is 0.4021 , which is more than the correlation of exports with outward spillovers at -0.1880 . The sum of absolute spillovers transmitted and received is also positively related to the sum of exports and imports (or the openness of an economy) at 0.3960 in our sample. These results attest to the difficulties in directly relating spillovers to trade, particularly for exports.

Agénor et al. (2017) show that the distribution of gains from macroprudential coordination is distorted toward larger emerging market economies and away from core economies. This is likely to cause political tensions in trying to coordinate with smaller emerging markets that end up benefiting less than larger emerging markets, and where most of the transfer will come from advanced economies. Furthermore, getting redistributions from emerging markets-even where they can be demonstrated to be welfare improving at the global level-may be politically contentious. It is worth noting that the Agénor et al. (2017) model has limitations and simplifications, including restricting nations to balanced budgets. So, there is a pressing need to assess these potential trade-offs further in more realistic modeling frameworks.

\section{CONCLUSION}

Quantifying spillovers and contagion between markets is challenging because of the changing nature of volatility in financial markets, the underlying trade and portfolio relationships, and, in the case of Asia, the region's rapid growth and development since 2000.

This paper examined the evidence on spillovers, contagion, and decoupling for 12 Asian markets, Australia, and the US (bringing the total sample to 14) using equity market indexes. Spillovers are modeled using VAR and we find distinct evidence of changes in the spillovers between these markets, with increasing evidence of growing effects over the four periods. The continued effects of the US markets on Asia are also apparent. There is a high degree of spillovers from the PRC and the US, both to each other and to other Asian markets. We find strong evidence of both contagion and decoupling effects using the US as the global mimicking factor. Asian markets show evidence of decoupling from the shocks in the US market during the GFC period. In other words, Asian markets were less influenced by the turmoil in US markets than would have been anticipated by the degree of spillovers evident in the pre-GFC period. The European debt crisis and the most recent periods also show signs of change in the transmission of events via the contagion route, although these effects do not bring the transmissions back to pre-GFC period levels.

Because of the growing importance of the PRC in the spillover analysis, we consider the possibility that the country may be acting as a source of contagion in Asian markets. We find evidence of contagion from the PRC to other Asian markets, especially during the European debt crisis period. But it is important to note that this is a prime example of where contagion could be considered a positive for recipient markets. During this period of global stress caused by the European debt crisis, the PRC effects helped to sustain higher returns for other markets. This is an instance where the PRC market is not the relevant indicator for the source of the global shock in detecting contagion emanating from a crisis. This is further evident when we use a two-factor specification where the PRC and the US represent potentially separable effects on the other markets. The interconnection between these two markets, evident in the spillover results, prevents this from being a suitable representation of independently identifiable contagion effects on Asian markets, resulting in the model's poor empirical characteristics. 
We consider evidence for whether the estimated spillover and contagion effects are related to the trading activity of the economies in the sample, as proposed in the literature on the importance of trade, and find mixed evidence of this effect in our results. But we do find evidence to support the importance of the economy size, at least to the extent that is both a recipient and transmitter of spillovers. GDP per capita is positively related with the receipt of spillovers; that is, it only seems to amplify spillovers. GDP and transmitted shocks are, on average, dampening. This fits with the role of the developed core economies as the core of financial markets, acting to absorb the shocks from periphery (emerging) markets and transmitting dampening effects back to the periphery, which is consistent with the hypothesis proposed by Kaminsky and Reinhart (2003). Evidence linking these effects to market size (measured as GDP) supports the arguments put forward in Agénor et al. (2017) that the global benefits of macroprudential policy coordination may be difficult to achieve because their benefits will primarily accrue to large emerging markets at the cost of the advanced markets. 


\section{REFERENCES}

Acemoglu, Daron, Asuman Ozdaglar, and Alireza Tahbaz-Salehi. 2015. "Systemic Risk and Stability in Financial Networks." American Economic Review 105 (2): 564-608.

Agénor, Pierre-Richard, Enisse Kharroubi, Leonardo Gambacorta, Giovanni Lombardo, and Luiz A. Pereira da Silva. 2017. "The International Dimensions of Macroprudential Policies." BIS Working Paper No. 643. Basel: Bank for International Settlements.

Aizenman, Joshua, Yothin Jinjarak, and Donghyun Park. 2015. "Financial Development and Output Growth in Developing Asia and Latin America: A Comparative Sectoral Analysis." NBER Working Paper No. 20917. Cambridge, MA: National Bureau of Economic Research.

Allen, Franklin, and Douglas Gale. 2004. "Competition and Financial Stability." Journal of Money, Credit and Banking 36 (3): 453-80.

Allen, William A., and Geoffrey Wood. 2006. "Defining and Achieving Financial Stability." Journal of Financial Stability 2 (2): 152-72.

Arslanalp, Serkan, Wei Liao, Shi Piao, and Dulani Seneviratne. 2016. "China's Growing Influence on Asian Financial Markets." IMF Working Paper No. 16/173. Washington, DC: International Monetary Fund.

Asian Development Bank (ADB). 2017. Asian Economic Integration Report 2017: The Era of Financial Interconnectedness. Manila.

Avdjiev, Stefan, Valentina Bruno, Catherine Koch, and Hyun Song Shin. 2018. "The Dollar Exchange Rate as a Global Risk Factor: Evidence from Investment.” BIS Working Paper No. 695. Basel: Bank for International Settlements.

Baur, Dirk G., and Renée A. Fry. 2009. “Multivariate Contagion and Interdependence.” Journal of Asian Economics 20 (4): 353-66.

Baur, Dirk, and Niels Schulze. 2005. "Coexceedances in Financial Markets: A Quantile Regression Analysis of Contagion.” Emerging Markets Review 6 (1): 21-43.

Beirne, John, Guglielmo Maria Caporale, Marianne Schulze-Ghattas, and Nicola Spagnolo. 2010. "Global and Regional Spillovers in Emerging Stock Markets: A Multivariate GARCH-in-Mean Analysis." Emerging Markets Review 11 (3): 250-60.

Billio, Monica, Mila Getmansky, Andrew W. Lo, and Loriana Pelizzon. 2012. "Econometric Measures of Connectedness and Systemic Risk in the Finance and Insurance Sectors." Journal of Financial Economics 104 (3): 535-59.

Botman, Dennis P. J., Irineu E. de Carvalho Filho, and Waikei Raphael Lam. 2013. "The Curious Case of the Yen as a Safe-Haven Currency: A Forensic Analysis.” IMF Working Paper No. 13/228. Washington, DC: International Monetary Fund. 
Busetti, Fabio, and Andrew Harvey. 2011. "When Is a Copula Constant? A Test for Changing Relationships." Journal of Financial Econometrics 9 (1): 106-31.

Caporin, Massimiliano, Loriana Pelizzon, Francesco Ravazzolo, and Roberto Rigobon. 2018. "Measuring Sovereign Contagion in Europe." Journal of Financial Stability 34: 150-81.

Chiang, Thomas C., Bang Nam Jeon, and Huimin Li. 2007. "Dynamic Correlation Analysis of Financial Contagion: Evidence from Asian Markets." Journal of International Money and Finance 26 (7): 1206-28.

Demirer, Mert, Francis X. Diebold, Laura Liu, and Kamil Yilmaz. 2018. "Estimating Global Bank Network Connectedness.” Journal of Applied Econometrics 33 (1): 1-15.

Diebold, Francis X., and Kamil Yilmaz. 2009. "Measuring Financial Asset Return and Volatility Spillovers, with Application to Global Equity Markets.” Economic Journal 119 (534): 158-71.

- 2012. "Better to Give than to Receive: Predictive Directional Measurement of Volatility Spillovers." International Journal of Forecasting 28 (1): 57-66.

-2014. "On the Network Topology of Variance Decompositions: Measuring the Connectedness of Financial Firms." Journal of Econometrics 182 (1): 119-34.

-2015. "Trans-Atlantic Equity Volatility Connectedness: US and European Financial Institutions, 2004-2014." Journal of Financial Econometrics 14 (1): 81-127.

Dungey, Mardi, Renée Fry, Brenda González-Hermosillo, and Vance L. Martin. 2005. "Empirical Modelling of Contagion: A Review of Methodologies." Quantitative Finance 5 (1): 9-24.

Dungey, Mardi, Renée Fry, and Vance L. Martin. 2004. "Currency Market Contagion in the Asia-Pacific Region." Australian Economic Papers 43 (4): 379-95.

Dungey, Mardi, John Harvey, Pierre L. Siklos, and Vladimir Volkov. 2018. "Signed Spillover Effects Building on Historical Decomposition." Tasmanian School of Business and Economics Discussion Paper Series No. 2017-11. University of Tasmania.

Dungey, Mardi, John Harvey, and Vladimir Volkov. 2018. "The Changing International Network of Sovereign Debt and Financial Institutions." Journal of International Financial Markets, Institutions and Money. https://doi.org/10.1016/j.intfin.2018.12.013.

Dungey, Mardi, Faisal Khan, and Mala Raghavan. 2018. "International Trade and the Transmission of Shocks: The Case of ASEAN-4 and NIE-4 Economies." Journal of Economic Modelling 72 (C): 109-21.

Dungey, Mardi, George Milunovich, Susan Thorp, and Minxian Yang. 2015. "Endogeneous Crisis Dating and Contagion Using Smooth Transition Structural GARCH." Journal of Banking and Finance 58: 71-79.

Dungey, Mardi, and Eric Renault. 2018. “Identifying Contagion.” Journal of Applied Econometrics 33 (2): 227-50. 
Dungey, Mardi, and Tugrul Vehbi. 2015. "The Influences of International Output Shocks from the US and China on ASEAN Economies." Journal of Asian Economics 39 (C): 59-71.

Dungey, Mardi, and Diana Zhumabekova. 2001. "Testing for Contagion Using Correlation: Some Words of Caution." Working Paper Series No. 2001-09. Federal Reserve Bank of San Francisco.

Elekdag, Selim, Phurichai Rungcharoenkitkul, and Yiqun Wu. 2012. "The Evolution of Asian Financial Linkages: Key Determinants and the Role of Policy." IMF Working Paper No. 12/262. Washington, DC: International Monetary Fund.

Forbes, Kristin J., and Roberto Rigobon. 2002. "No Contagion, Only Interdependence: Measuring Stock Market Comovements.” Journal of Finance 57 (5): 2223-61.

Fu, Xiaoqing Maggie, Yongjia Rebecca Lin, and Philip Molyneux. 2014. "Bank Competition and Financial Stability in Asia-Pacific.” Journal of Banking and Finance 38 (January): 64-77.

Giannetti, Mariassunta, and Luc Laeven. 2016. "Local Ownership, Crises and Asset Prices: Evidence from US Mutual Funds.” Review of Finance 20 (3): 947-78.

Haldane, Andrew G. 2009. "Rethinking the Financial Network." Speech delivered at the Financial Student Association, Amsterdam.

Hwang, Eugene, Hong-Ghi Min, Bong-Han Kim, and Hyeongwoo Kim. 2013. "Determinants of Stock Market Comovements among US and Emerging Economies during the US Financial Crisis." Economic Modelling 35: 338-48.

Kaminsky, Graciela L., and Carmen Reinhart. 2002. "Financial Markets in Times of Stress." Journal of Development Economics 69 (2): 451-70.

- 2003. "The Center and the Periphery: The Globalization of Financial Turmoil." NBER Working Paper No. 9479. Cambridge, MA: National Bureau of Economic Research.

Kim, Bong-Han, Hyeongwoo Kim, and Bong-Soo Lee. 2015. "Spillover Effects of the US Financial Crisis on Financial Markets in Emerging Asian Countries." International Review of Economics and Finance 39 (C): 192-210.

Lucking, Brian, Nicholas Bloom, and John Van Reenen. 2018. “Have R\&D Spillovers Changed?” NBER Working Paper No. 24622. Cambridge, MA: National Bureau of Economic Research.

Mobarek, Asma, Gulnur Muradoglu, Sabur Mollah, and Ai Jun Hou. 2016. "Determinants of Time Varying Co-Movements among International Stock Markets during Crisis and Non-Crisis Periods." Journal of Financial Stability 24 (June): 1-11.

Rigobon, Roberto. 2002. "The Curse of Non-Investment Grade Countries." Journal of Development Economics 69 (December): 423-49. 
Sander, Harald, and Stefanie Kleimeier. 2003. "Contagion and Causality: An Empirical Investigation of Four Asian Crisis Episodes." Journal of International Financial Markets, Institutions and Money 13 (2): 171-86.

Sewraj, Deeya, Bartosz Gebka, and Robert D. J. Anderson. 2018. "Identifying Contagion: A Unifying Approach." Journal of International Financial Markets, Institutions and Money 55 (C): 224-40.

Supple, Barry. 1959. Commercial Crisis and Change in England 1600-1642. Cambridge Studies in Economic History. Cambridge: Cambridge University Press.

Van Rijckeghem, Caroline, and Beatrice Weder. 2001. "Sources of Contagion: Is It Finance or Trade?" Journal of International Economics 54 (2): 293-308.

Yilmaz, Kamil. 2010. "Return and Volatility Spillovers among the East Asian Equity Markets." Journal of Asian Economics 21 (3): 304-13.

Zigraiova, Diana, and Tomas Havranek. 2016. "Bank Competition and Financial Stability: Much Ado about Nothing?” Journal of Economic Surveys 30 (5): 944-81. 


\section{Changing Vulnerability in Asia: Contagion and Systemic Risk}

This paper shows how the international financial network has developed as Asia became an increasingly important market since the year 2000. It tracks progress through the 1997-1998 Asian financial crisis, the 2008 global financial crisis, and the European debt crisis. The study shows that developed markets can act as a bridge for emerging markets to access the global financial network, overcoming the information asymmetry that exists between emerging markets and the global network. The authors recommend that financial regulators take caution in adopting network policies that could disproportionately benefit larger emerging markets.

\section{About the Asian Development Bank}

ADB is committed to achieving a prosperous, inclusive, resilient, and sustainable Asia and the Pacific, while sustaining its efforts to eradicate extreme poverty. Established in 1966, it is owned by 68 members49 from the region. Its main instruments for helping its developing member countries are policy dialogue, loans, equity investments, guarantees, grants, and technical assistance. 